\title{
Achieving the promise of integration in social-ecological research: a review and prospectus
}

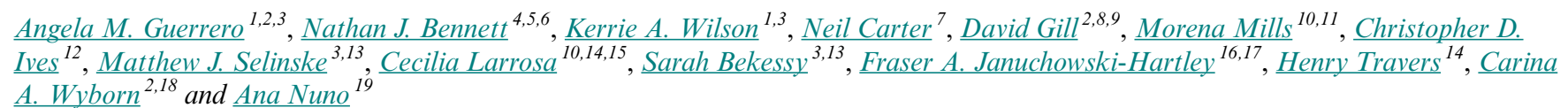

\begin{abstract}
An integrated understanding of both social and ecological aspects of environmental issues is essential to address pressing sustainability challenges. An integrated social-ecological systems perspective is purported to provide a better understanding of the complex relationships between humans and nature. Despite a threefold increase in the amount of social-ecological research published between 2010 and 2015, it is unclear whether these approaches have been truly integrative. We conducted a systematic literature review to investigate the conceptual, methodological, disciplinary, and functional aspects of social-ecological integration. In general, we found that overall integration is still lacking in social-ecological research. Some social variables deemed important for addressing sustainability challenges are underrepresented in social-ecological studies, e.g., culture, politics, and power. Disciplines such as ecology, urban studies, and geography are better integrated than others, e.g., sociology, biology, and public administration. In addition to ecology and urban studies, biodiversity conservation plays a key brokerage role in integrating other disciplines into social-ecological research. Studies founded on systems theory have the highest rates of integration. Highly integrative studies combine different types of tools, involve stakeholders at appropriate stages, and tend to deliver practical recommendations. Better social-ecological integration must underpin sustainability science. To achieve this potential, future social-ecological research will require greater attention to the following: the interdisciplinary composition of project teams, strategic stakeholder involvement, application of multiple tools, incorporation of both social and ecological variables, consideration of bidirectional relationships between variables, and identification of implications and articulation of clear policy recommendations.
\end{abstract}

Key Words: human-environment systems; interdisciplinary; social-ecological systems; stakeholder participation; sustainability science

\section{INTRODUCTION}

People and nature are inextricably linked. Overcoming pressing sustainability challenges thus requires an integrated socialecological science (Liu et al. 2007). This more integrative approach provides a better understanding of systems involving people and natural resources than focusing only on unidirectional relationships, e.g., the human impacts on nature, ecosystem services, and so forth, or on single-component effects, e.g., biological or socioeconomic impacts on fish stocks (Ostrom 2007, Liu et al. 2015). For example, understanding and attending to sustainability challenges in the world's fisheries requires that biological aspects of fish stocks are considered alongside the livelihoods of coastal communities, the management of other protein sources, and the political and economic interests of largescale commercial enterprises and governments. Likewise, addressing the recovery of endangered species requires understanding the human activities affecting the viability of the species and also how species dynamics affect human livelihoods. Addressing sustainability challenges requires a shift in focus: from seeing people and nature as separate systems to seeing them as two interacting components of a complex, dynamic, and integrated system (Pollnac et al. 2010, Mace 2014, Fischer et al. 2015).

Social-ecological systems (SES) research sees a delineation between society and the environment as artificial and arbitrary, encouraging a holistic assessment of the dynamics of environmental and social systems (Milner-Gulland 2012, Fischer et al. 2015, Van Noorden 2015). In particular, humans and ecosystems interact creating dynamic feedback loops across multiple interlinked scales (Liu et al. 2007). These interactions and feedbacks can have a positive or negative effect, i.e., benefit or harm, on both social and ecological system components (Daw et al. 2015, Bennett et al. 2016). Left unchecked, these feedbacks can produce regime shifts to undesirable ecosystem states (Biggs et al. 2009, Hicks et al. 2016a) or social-ecological poverty traps (Cinner 2011), or they can lead to unanticipated consequences (Larrosa et al. 2016, Carter et al. 2017). Thus, interdisciplinary research frameworks, methods, and approaches that further

\footnotetext{
${ }^{1}$ School of Biological Sciences, The University of Queensland, ${ }^{2}$ Luc Hoffmann Institute, ${ }^{3}$ ARC Centre of Excellence for Environmental Decisions, The University of Queensland, ${ }^{4}$ Institute for Resources, Environment and Sustainability, University of British Columbia, Vancouver, Canada, ${ }^{5}$ University of Nice Sophia Antipolis, Nice, France, ${ }^{6}$ Center for Ocean Solutions, Stanford University, California, USA, ${ }^{7}$ Human-Environment Systems Center, Boise State University, ${ }^{8}$ National Socio-Environmental Synthesis Center (SESYNC), Annapolis, Maryland, USA, ${ }^{9}$ Nicholas School of the Environment, Duke University, Beaufort, North Carolina, USA, ${ }^{10}$ Department of Life Sciences, Imperial College London, ${ }^{11}$ Centre for Biodiversity and Conservation Science, The University of Queensland, St. Lucia, Australia, ${ }^{12}$ School of Geography, University of Nottingham, UK, ${ }^{13}$ Interdisciplinary Conservation Science Research Group, School of Global, Urban and Social Studies, RMIT University, ${ }^{14}$ Interdisciplinary Centre for Conservation Science, Department of Zoology, University of Oxford, ${ }^{15}$ Department of Biological Sciences, National University of Singapore, ${ }^{16}$ UMR 248 MARBEC, IRD-CNRS-UM-IFREMER 9190, UMR 250 ENTROPIE, Université Montpellier, Montpellier, France, ${ }^{17}$ Department of Biosciences, College of Science, Swansea University, Swansea, UK, ${ }^{18}$ College of Forestry and Conservation, University of Montana, ${ }^{19}$ Centre for Ecology and Conservation, College of Life and Environmental Sciences, University of Exeter, Penryn, Cornwall, UK
} 
Table 1. The four dimensions of social-ecological integration considered in this study, with descriptions, specific research questions, and references used to illustrate relevance of different factors.

\begin{tabular}{llll}
\hline \hline $\begin{array}{l}\text { Dimensions of } \\
\text { Integration }\end{array}$ & Description & Review Questions $^{\dagger}$ \\
\hline Conceptual integration & $\begin{array}{l}\text { The extent to which a study considers both } \\
\text { social and ecological system components } \\
\text { and the two-way interactions between } \\
\text { social and ecological systems. }\end{array}$ & $\begin{array}{l}\text { 1. Are both social and ecological } \\
\text { components of the system considered? }\end{array}$ & 2. Is the direction of interaction between \\
& (2013), Liu et al. (2015), Chan & et al. (2016)
\end{tabular}
social and ecological components considered (uni- or bidirectional)?

3. What is the value orientation (ecocentric, anthropocentric, or relational ${ }^{+}$) driving the integration?

Methodological integration

The incorporation of multiple frameworks, tools, and/or theories within a single study and the use of both qualitative and quantitative methods.

Disciplinary integration ${ }^{\S}$

The inclusion of approaches from multiple disciplines within a single study.

Functional integration
The bridging of science with policy or practice through the integration of different stakeholders and researchers in the research process and the merging of conceptual with problem-solving approaches to identify actionable recommendations.
4. What aspects (social and ecological variables) are being integrated?

5. What are the frameworks, tools, and theories being used for integrating social and ecological aspects? How are they being applied?

6. To what degree are qualitative and quantitative methods being integrated? 7. Which disciplines are represented in the research?

8. What disciplines are being integrated? 9. To what degree were stakeholders involved? Who and when?

10. Were practical recommendations provided?
Schlüter et al. (2012), Binder et al. (2013)

Mascia et al. (2003), Manfredo et al. (2014), Brown et al. (2015)

Knight et al. (2006), Reed (2008)

See Appendix 3 for exact wording of review questions.

* Ecocentric: defines the ecological system based on its internal functioning and recognizes that nature has value independent of people.

Anthropocentric: defines the ecological system based on its utility for humans or instrumental value. Relational: defines the ecological systems based on how humans relate to it; pertains to all manner of relationships between people and nature.

${ }^{\S}$ We use the classification system included in Thomson Reuters' Web of Science database.

understanding of social-ecological dynamics are essential for the design of more effective policies and interventions for sustainability challenges (Levin et al. 2013, Liu et al. 2015).

The role and importance of SES research in advancing sustainability is increasingly acknowledged in the literature (Kajikawa et al. 2014, Fischer et al. 2015). Through SES research, diverse systems, e.g., social, economic, and ecological, and disciplines, e.g., political science, public health, ecology, and sociology, can be integrated to bridge sustainability topics such as biodiversity conservation, agricultural management, sustainable development, and environmental management (Kajikawa et al. 2014). The number of SES research publications rose threefold from 2010 to 2015 (Fig. A1.1 in Appendix 1), and there have been numerous analytical frameworks, methods, and approaches applied to achieve better integration (Schlüter et al. 2012, Binder et al. 2013). However, the potential of a mainstream and integrated SES approach in the environmental sciences has not yet been fully realized (Liu et al. 2015, Bennett et al. 2017). Literature on SES research points to different ways in which integration can occur, i.e., conceptual, disciplinary, methodological, and functional, which we define and for which we provide review questions and references in Table 1. We propose that each dimension, although potentially overlapping, highlights an important aspect of integration, distinguishing the way the problem is conceptualized from the methodological and practical approaches used to address it. Thus, together these four dimensions make up a comprehensive typology, which challenges the generalized narratives about "integrative research." The extent to which integration has been achieved in past SES research is unclear, despite such knowledge potentially providing critical insights into how to conduct more effective and meaningful SES research.

We systematically review how SES research has been conducted in the environmental, sustainability, and natural resource management literatures with a focus on the extent to which conceptual, disciplinary, methodological, and functional integration is achieved (Table 1). Our review includes different terminologies used within SES research, including socialecological, social-environmental, and human-environment. Building on discussions of the significant barriers and challenges 
to integration (Binder et al. 2013, Larrosa et al. 2016), we focus on identifying opportunities to increase integrative SES research. Ultimately, we aim to enhance the degree of integration in SES research, thus advancing both the science and application of crossdisciplinary knowledge contributing to better management and improved environmental and social outcomes.

\section{METHODS}

Focusing on four dimensions of social-ecological integration, i.e., conceptual, disciplinary, methodological, and functional (Table 1), we identified key questions based on available literature and the knowledge and experiences of a team of 13 researchers with expertise in SES research and a background in biology, community development, conservation science, decision science, ecology, economics, engineering, environmental management, fisheries, geography, sustainability, and urban planning. We then conducted an extensive multistep systematic literature review and analysis as described subsequently.

The questions related to the four types of social-ecological integration we explored are presented in Table 1. Four questions relate to conceptual integration, i.e., consideration of social and ecological components, direction of effects, and value orientation (questions 1-4); two relate to methodological integration, i.e., incorporation of frameworks, tools, and theories, and the use of qualitative and quantitative approaches (questions 5-6); two relate to disciplinary integration, i.e., inclusion of multiple disciplines (questions 7-8); and two relate to functional integration, i.e., bridging of science with policy or practice (questions 9-10). Acknowledging the challenge of robustly assessing socialecological integration, we also included a question to assess overall integration (see wording in Appendix 3). This question reflects the broader way in which the social-ecological concept is understood in the literature, and as such, it is designed to assess the degree to which the social and the ecological aspects of an issue are treated as part of the same system (Berkes et al. 2001, 2003, Gunderson and Holling 2002).

We searched the Web of Science database with a predetermined set of criteria (Appendix 2) to capture papers that apply or consider both ecological and social information in environmental-related topics. At the search date (18 November 2015), this set of criteria resulted in 1760 papers. All abstracts were randomly assigned and read by A. M. Guerrero and A. Nuno, who assessed if each paper fit four predefined criteria: (1) purported description or application of a social-ecological approach, (2) environmental related, (3) inclusion of environmental data, and (4) inclusion of social data. Review papers were excluded, and this resulted in 700 suitable papers. Appendix 2 includes a summary of excluded papers.

One hundred and twenty $(17.1 \%)$ of these 700 papers were then randomly selected for review. We codesigned the review protocol and reviewed the selected papers based on the questions identified (Table 1). Coauthors and reviewers were selected by A. Nuno and A. M. Guerrero because of their current roles and backgrounds working in SES research. Responses were collected using a standardized online survey tool. The exact wording of the review questions, and the guidelines and definitions used to help reviewers, e.g., of concepts and answer categories, are presented in Appendix 3. Potential reviewer biases were addressed by allocating two reviewers to each paper and, in case of scoring disagreements, assigning a third person (A. M. Guerrero and A. Nuno) to moderate and, when required, facilitate a discussion to find consensus. Out of 120 papers reviewed, $4(3.3 \%)$ papers were classified as "reviews," and $6(5 \%)$ papers did not include both social and environmental data; thus, these 10 papers $(8.3 \%)$ were excluded. Results from reviewing the remaining 110 papers were then analyzed descriptively and summarized (Appendix 4). As some questions only applied to empirical studies, we indicate, where relevant, if sample size refers to the subsample of 110 papers or to empirical studies only (101 papers).

Measures of integration for the conceptual, methodological, and functional dimensions were obtained from summarizing responses to review questions (questions 1-4, 5-6, and 9-10 in Table 1, respectively). A measure for disciplinary integration (questions 7 and 8 in Table 1) was obtained by employing graphtheoretic methods. First, disciplines were assigned to papers based on the classification system used by the Web of Science database; in this system, the journal in which a publication has appeared determines the research area to which the publication belongs. From this information, a graph matrix was developed indicating the number of times two disciplines were assigned to the same paper. This was then transformed into a network where each discipline is represented by a node, and they are linked if they are identified in the same paper. The algorithm used in the graphtheoretic analysis assigns locations to nodes, i.e., disciplines, such that nodes with the smallest path lengths are closer together (Krempel 2011), thus indicating that a discipline placed far from the rest of the network has low integration into SES research. We also used the "betweenness centrality" metric (Freeman 1977), which has been applied to a variety of network types including citation data (Hicks et al. 2010), and has been used before as an indicator of journal interdisciplinarity (Leydesdorff 2007). It accounts for indirect links and measures how often a node is on the shortest path between other nodes in the network; the higher the betweenness centrality score, the more that particular node (discipline) connects other nodes (other disciplines) that would otherwise be disconnected. We have used it to reflect the role that each discipline plays in integrating diverse disciplines in SES research. A similar approach was employed to complement descriptive measures for conceptual integration. However, in this network the nodes denote each of the different variables (social or ecological) incorporated in SES studies, and two nodes are linked when the two variables are incorporated within the same study. Again, we used graph-theoretic methods to visually map integration of social and ecological variables and used the betweenness centrality measure to reflect the extent to which each variable is integrated with other variables to SES research.

The reviewers provided a measure for overall integration (see Appendix 3, question 11) using a Likert scale (1 to 5) where 1 was "minimal integration" and 5 was "a great amount of integration." We explored potential relationships between the overall integration score and all other measured aspects (Table 1) and assessed the role played by each measure of integration across the four dimensions against the overall integration score. To account for the quantitative nature of Likert scales, but without making assumptions about the distance between ordered categories, ordered logistic regressions were used to assess relationships. To investigate potential effects on binary variables such as occurrence of stakeholder involvement, generalized linear models with quasibinomial error distribution, to account for overdispersion, and a 
Fig. 1. Social and ecological variables captured in social-ecological systems $(\mathrm{SES})$ research studies $(\mathrm{n}=$ 101 empirical studies) and how they are integrated. The graph was generated using a spring embedding algorithm in the Netdraw software package, which assigns locations to nodes such that nodes with the smallest path lengths are closer together (Krempel 2011). Thus, an aspect placed far from the rest of the network indicates low integration of this aspect into SES research. In addition, the bigger the size of the node, the higher the betweenness score, suggesting that a particular variable is playing an important role in integrating other variables into SES research.

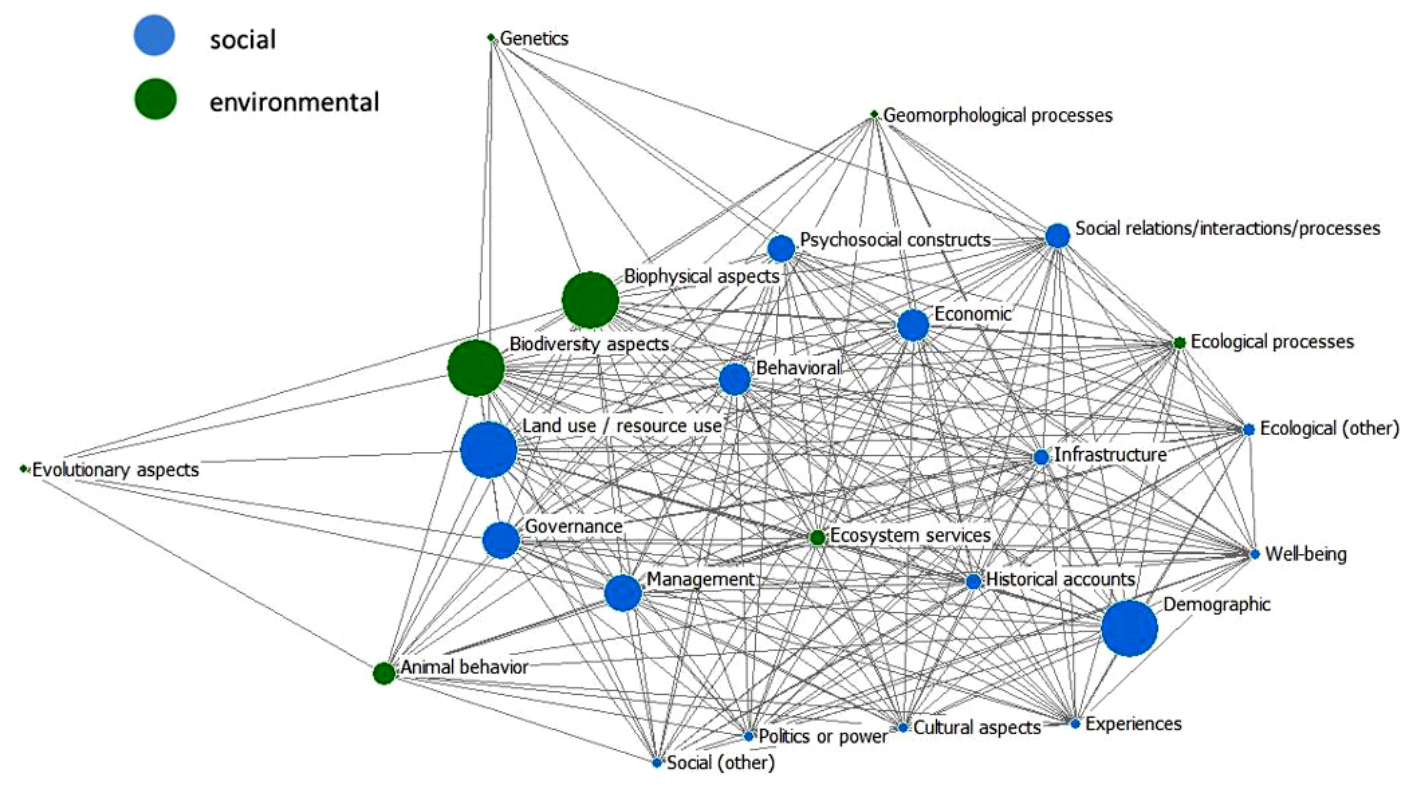

logit link were fitted. Statistical analyses were conducted in $\mathrm{R}$, version 3.3.2 (R Foundation for Statistical Computing 2016). Because of the wide range of possible answer categories, e.g., types of methods, and subsequent small sample sizes per level, a minimum amount of 10 studies per category was required for inclusion and comparison in the statistical models.

\section{RESULTS}

\section{Overall integration}

The median overall integration score for all papers reviewed was $3($ mean $=2.8$, standard deviation $[\mathrm{SD}]=1.2$; scale of 1 to 5$)$. Close to half of all papers received the median score for overall integration, whereas a fifth were given the lowest score (Fig. A4.1 in Appendix 4).

\section{Conceptual integration}

Out of the randomly selected 110 papers meeting our predefined criteria, 101 were empirical studies presenting observation or experimental data, and 9 focused on conceptual contributions. Approximately two-thirds (64\%) of the empirical papers captured or considered bidirectional interactions. When comparing bidirectionality among studies that used different methodological approaches, i.e., modelling tools, conceptual models, participatory approaches, statistical tools, comparison of social and ecological data, and social-ecological frameworks, we found some evidence, although nonconclusive, that studies using modelling tools (excluding statistical models) or social-ecological frameworks were more likely to consider bidirectional interactions $(\mathrm{t}=1.67, \mathrm{p}<0.1$ and $\mathrm{t}=1.70, \mathrm{p}=0.09$, respectively).
The majority of SES research reflects an anthropocentric perspective $(81 \%)$, with $10 \%$ and $7 \%$ of papers reflecting ecocentric and relational perspectives, respectively. The most common variables incorporated in empirical SES studies are land use or resource use variables, followed by biophysical and economic variables $(n=75,72$, and 62 , respectively; see Table A4.1 in Appendix 4 for detailed results). In addition, network analysis results show that biodiversity and demographic variables are more frequently integrated with other variables in SES research, in addition to land use and biophysical variables (Fig. 1 and Table A4.1 in Appendix 4). Overall integration ratings were not associated with diversity of, i.e., number of, social and ecological variables used $(t=-0.26, p=0.79$; Fig. A4.2 in Appendix 4). So although incorporating a greater diversity of social and ecological variables captures more of the socialecological system, these results suggest current applications are falling short in other aspects of conceptual integration, for example, failing to capture bidirectional interactions.

\section{Methodological integration}

SES research is characterized by the use of a variety of tools that integrate social with environmental aspects, including socialecological frameworks, modelling, and spatial, participatory, and statistical tools (Fig. A4.3 in Appendix 4). Their applications and purposes vary considerably. For example, most tools are used or developed to describe a social-ecological system ( $84 \%$; Table 2$)$, either to understand its components, its relationships, or a problem or gap in understanding. This is especially the case for papers involving social-ecological frameworks, conceptual 
Fig. 2. How different tools are being used or proposed to be used in social-ecological systems studies, as a proportion of the total number of studies found to apply each tool. A study can use a tool in more than one way.

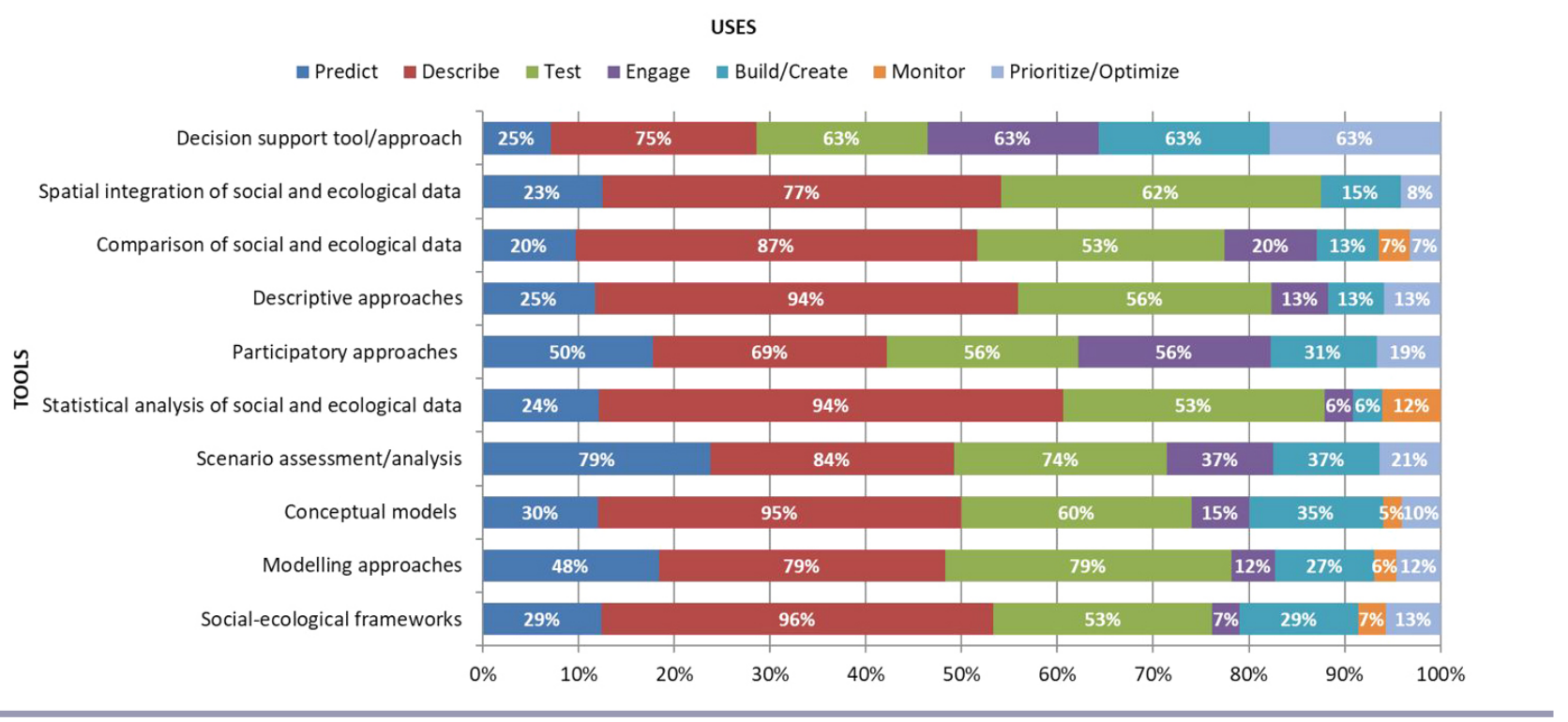

models, and statistical or descriptive approaches (Fig. 2). Studies designed to test management alternatives, strategies or policies, or hypotheses, are also common (Table 2), especially for those studies applying modelling and scenario assessment tools (Fig. 2). Papers focusing on identifying a desired way forward or on predicting a future change are less common (Table 2). However, prediction is common among the studies using scenario assessment, modelling, and participatory tools (Fig. 2). In addition, stakeholder engagement is common among SES studies applying decision support tools and participatory approaches (Fig. 2).

We found that the number of tools applied by empirical studies increased with higher overall integration scores $(t=2.28, p=0.02$; Table A4.2 in Appendix 4). In addition, higher levels of integration were found in studies in which tools such as modelling approaches, spatial integration tools, and the driver-pressurestate-impact-response framework were used, albeit with small sample sizes (Table A4.3 in Appendix 4). Studies that indicated the use of any theories, e.g., resilience theory, common pool resource theory, and adaptive cycle theory, on average were not found to show higher integration; however, when comparing integration among the theories most commonly used in the reviewed studies, i.e., resilience theory, common pool resource theory, and systems theory, studies using systems theory had significantly higher integration scores $(\mathrm{t}=2.09, \mathrm{p}<0.04$; Table A4.4 in Appendix 4). Finally, we found that a third of empirical SES studies integrate qualitative and quantitative methods, whereas half of SES research uses quantitative-only methods.

\section{Disciplinary integration}

Our analysis shows that SES research is integrating some disciplines better than others (Fig. 3). Given our focus on environmental-related literature, a large proportion of the SES studies in our review were assigned to environmental sciences and environmental studies ( $n=345$ and $n=339$, respectively). Of the distinct disciplines found in SES research publications, ecology

Table 2. Ways in which tools are applied in social-ecological systems research, based on subset of 110 randomly selected papers.

\begin{tabular}{|c|c|c|}
\hline & $\begin{array}{l}\text { Num- } \\
\text { ber of } \\
\text { Papers }\end{array}$ & $\begin{array}{c}\text { Percent } \\
\text { Out of } \\
110\end{array}$ \\
\hline $\begin{array}{l}\text { Describe: } \\
\text { to describe or understand the system, e.g., elements, } \\
\text { relationships, problems, or gaps in understanding, or } \\
\text { to describe historical changes }\end{array}$ & 92 & 84 \\
\hline $\begin{array}{l}\text { Test: } \\
\text { to identify and test management alternatives, } \\
\text { strategies, or policies, or to test hypotheses }\end{array}$ & 65 & 59 \\
\hline $\begin{array}{l}\text { Predict: } \\
\text { to identify a desired way forward or to predict future } \\
\text { change (model future states) }\end{array}$ & 34 & 31 \\
\hline $\begin{array}{l}\text { Build: } \\
\text { to build or create tools, methods, or theories }\end{array}$ & 24 & 22 \\
\hline $\begin{array}{l}\text { Engage: } \\
\text { to engage stakeholders }\end{array}$ & 14 & 13 \\
\hline $\begin{array}{l}\text { Optimize: } \\
\text { to identify priorities or "optimal" solutions }\end{array}$ & 12 & 11 \\
\hline $\begin{array}{l}\text { Monitor: } \\
\text { to monitor or evaluate policies }\end{array}$ & 7 & 6 \\
\hline
\end{tabular}

${ }^{\dagger}$ More than one category per study allowed.

has a high representation $(\mathrm{n}=379)$, followed by biodiversity conservation and geography $(\mathrm{n}=75$ and 56, respectively; Table A4.5 in Appendix 4). Graph-theoretic analysis results indicate that disciplines such as ecology, urban studies, geography, geosciences, and economics are more integrated into SES research than disciplines such as biology, public administration, sociology, 
Fig. 3. Disciplinary integration of social-ecological systems (SES) studies based on abstract review $(\mathrm{n}=$ 700). Disciplines were assigned to papers based on the classification system used by the Web of Science database according to journal. Given our focus on environmental-related literature, the majority of the SES studies in our review were assigned to either environmental studies or environmental sciences. The graph was generated using a spring embedding algorithm in the Netdraw software package, which assigns locations to nodes such that nodes with the smallest path lengths are closer together (Krempel 2011). Thus, a discipline placed far from the rest of the network indicates low integration of this discipline into SES research. The bigger the size of the node, the higher the betweenness score for the corresponding discipline, thus suggesting an important role in integrating other disciplines to SES research. The width of the line connecting nodes denotes how often two disciplines are being integrated.

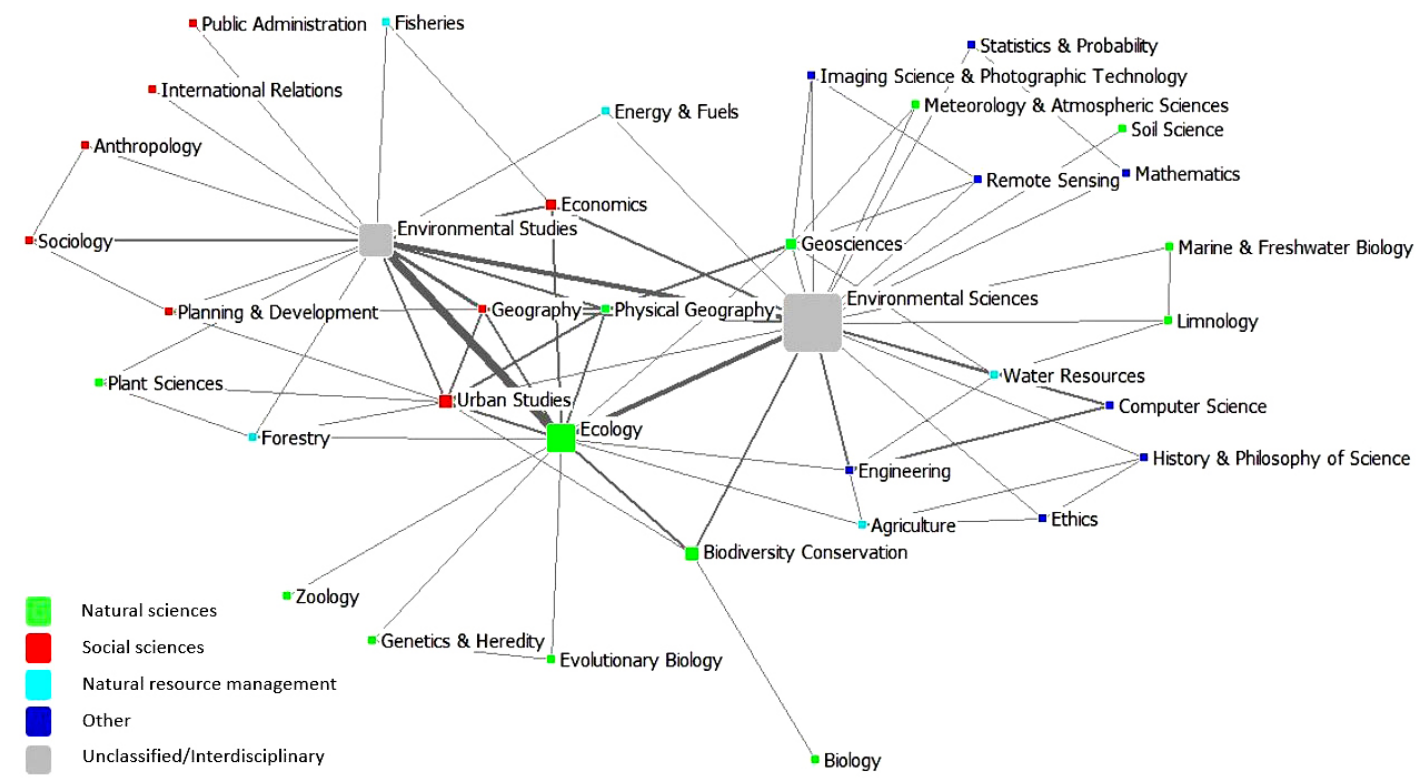

anthropology, and marine and freshwater biology (Fig. 3). The betweenness centrality scores were higher for environmental science and environmental studies, followed by ecology, biodiversity conservation, and urban studies $(n=342, n=177, n$ $=137, \mathrm{n}=34$, and $\mathrm{n}=33$, respectively; mean $=21.4, \mathrm{SD}=65.2$; Table A4.5 in Appendix 4), suggesting they play a "brokerage" role in the disciplinary integration in SES research.

\section{Functional integration}

When compared with quantitative studies, stakeholders were more likely to be involved in qualitative studies $(\mathrm{t}=2.40, \mathrm{p}=0.02)$ or those that combine qualitative with quantitative methods $(\mathrm{t}=$ $3.25, \mathrm{p}=0.002$; Table 3). However, results indicate that involving stakeholders may not necessarily result in better integration overall $(\mathrm{t}=-1.34, \mathrm{p}=0.18$; Table A4.6 in Appendix 4). However, when comparing potential effects of involving stakeholders at different phases, i.e., problem definition, study design, data collection, analysis/assessment, and/or delivery of outputs, on overall integration scores, studies involving stakeholders in the design phase of a study were rated significantly higher for overall integration $(\mathrm{t}=2.46, \mathrm{p}<0.02$; Table 4$)$. We also found some evidence that studies that provide recommendations for practice or policy are more likely to be better integrated compared to studies that do not provide recommendations (Table 5), although significant only at the 0.1 level $(t=1.72, \mathrm{p}=0.09)$.
Table 3. Stakeholder inclusion by type of approach (qualitative vs. quantitative).

\begin{tabular}{lcc}
\hline \hline & $\begin{array}{c}\text { No } \\
\text { Stakeholders } \\
\text { Involved (\%) }\end{array}$ & $\begin{array}{c}\text { Stakeholders } \\
\text { Involved (\%) }\end{array}$ \\
\hline Qualitative $(\mathrm{n}=14)$ & 36 & 64 \\
Quantitative $(\mathrm{n}=51)$ & 71 & 29 \\
Both $(\mathrm{n}=36)$ & 36 & 64 \\
\hline
\end{tabular}

\section{DISCUSSION}

It is commonly claimed that sustainable environmental management solutions are more likely when both social and ecological components are considered (Ostrom 2007). However, our results indicate that, although moderate levels of integration are common as suggested by the clustering of publications around the median integration levels ( 3 on the Likert scale), integration of SES research is still lacking across the combination of conceptual, methodological, disciplinary, and functional dimensions. Studies that are able to better integrate human and environmental aspects apply a diversity of tools, involve a variety of stakeholders during the design phase, and often result in practical recommendations. Studies that use modelling tools or 
social-ecological systems frameworks are better able to capture the bidirectional interactions between social and environmental components. These results highlight how decisions about problem framing, methods, interdisciplinarity, and stakeholder participation are important for integration. Subsequently, we briefly situate our results within the literatures on conceptual, methodological, disciplinary, and functional integration.

Table 4. Comparison of integration ratings across the different phases at which stakeholders were involved in social-ecological studies. A study could involve stakeholders in more than one study phase. When comparing potential effects of involving stakeholders at different phases, i.e., problem definition, study design, data collection, analysis/assessment, and/or delivery of outputs, on overall integration scores, studies involving stakeholders in the design phase of a study were rated significantly higher for overall integration $(t=2.46, p<0.02$; other phases: $p$ $>0.1$; ordered logistic regression).

\begin{tabular}{lcc}
\hline \hline $\begin{array}{l}\text { Study Stage at Which } \\
\text { Stakeholders Were Included }\end{array}$ & Count & $\begin{array}{l}\text { Integration Rating } \\
\text { (average score 2.8) }\end{array}$ \\
\hline Problem definition & 13 & 3.0 \\
Study design & 11 & 3.6 \\
Data collection & 33 & 2.5 \\
Analysis/assessment & 15 & 2.9 \\
Delivery of outputs & 5 & 3.2 \\
\hline
\end{tabular}

Table 5. Comparison of integration ratings across studies providing different levels of recommendations.

\begin{tabular}{|c|c|}
\hline & $\begin{array}{l}\text { Average } \\
\text { Rating }\end{array}$ \\
\hline $\begin{array}{l}\text { 1. No recommendations for policy or practice are identified ( } \mathrm{n} \\
=11 \text { ). }\end{array}$ & 2.2 \\
\hline $\begin{array}{l}\text { 2. No recommendations are identified, but they could have } \\
\text { been inferred from the results }(n=19) \text {. }\end{array}$ & 2.8 \\
\hline $\begin{array}{l}\text { 3. Some recommendations are provided, but they are too } \\
\text { general, or it is unclear how they follow from the results }(n= \\
\text { 28). }\end{array}$ & 2.5 \\
\hline $\begin{array}{l}\text { 4. Provide recommendations that follow from their results }(n= \\
\text { 40). }\end{array}$ & 3.1 \\
\hline $\begin{array}{l}\text { 5. Provide an extensive and clear list of recommendations that } \\
\text { follow from their results }(n=3) \text {. }\end{array}$ & 3.3 \\
\hline Grand total & 2.8 \\
\hline
\end{tabular}

\section{Conceptual integration}

At a fundamental level, integration in SES research requires studies to consider both social and ecological aspects, but we found conceptual integration in SES research is still lacking. This is reflected in the underrepresentation of some social variables deemed important for addressing sustainability challenges, e.g., culture, politics, and power (Fig. 1 and Table A4.1 in Appendix 4), and by the results of our initial abstract review, in which a quarter of the initially identified SES studies were excluded because they focused exclusively on social variables (Appendix 2). These results are consistent with Rissman and Gillon (2017) who found that one-third of SES research studies included only social aspects.
The need for the integration of both social and environmental aspects has been well expressed in the academic literature (Ostrom 2007, Pollnac et al. 2010, Bennett et al. 2017). Depending on the system of interest, some aspects, e.g., cultural connections, participation in management, strong institutions, and environmental refuges, can be critical for system dynamics, and thus excluding them from planning could lead to management failure (Ban et al. 2013, Cinner et al. 2016). Understanding the suite of social conditions, e.g., wealth or poverty, demographics, culture, politics, and power, and actions, e.g., harvesting and management, that might be either supporting or undermining management effectiveness is critical for improving sustainability (Reyers et al. 2013, Hicks et al. 2016b, Finkbeiner et al. 2017).

Some of the least integrated variables are in the "pure" biological sciences, e.g., evolution, genetics, and animal behavior (Fig. 1). Applied science in these fields may not be as well developed as with other variables that are inherently more integrated, e.g., ecosystem services. However, these variables might become more integrated with time as their applicability to management is further developed (e.g., Anthony and Blumstein 2000, Hoban et al. 2013). For example, decision makers generally have a weak understanding of genetics, which is needed for successful monitoring and management interventions for conserving genetic diversity (Hoban et al. 2013). Conservation genetics can be better integrated into management through partnerships between geneticists and policy makers (Hoban et al. 2013). Likewise, the potential for integrating animal behavior with other social-ecological variables is demonstrated in the developing work on human-wildlife conflict (Carter et al. 2012, 2017).

Our finding that two-thirds of SES studies consider bidirectional interactions between social and ecological components is encouraging. This is essential if we want to understand systems dynamics or identify potential unintended feedback effects of conservation interventions, which may lead to inefficient or perverse outcomes (Larrosa et al. 2016). Although our results suggest the benefit of applying social-ecological frameworks, other studies have suggested great variation in the extent to which specific frameworks consider bidirectional interactions (Binder et al. 2013). For example, frameworks such as the humanenvironment systems framework, the management strategy evaluation framework, and the SES framework consider bidirectional interactions and thus are well positioned to contribute to SES research (Ostrom 2007, Svarstad et al. 2008, Bunnefeld et al. 2011). However, the challenge in the application of these frameworks is to empirically capture and test some of these bidirectional relationships, e.g., impacts and benefits, over time. This will require more sophisticated study designs, methods, resources, and analyses.

\section{Methodological integration}

Our results suggest that studies that apply a greater number of tools achieve a higher level of integration. This might be because understanding different social and ecological aspects, as well as their interactions, is likely to require the application of multiple tools. There are multiple benefits that can be gained from employing diverse or mixed-methods approaches. A diverse methodological tool kit supports triangulation to better 
understand the problem. For example, comprehensive models of ecological system dynamics can be achieved using available data of empirical observations in combination with stakeholder knowledge gathered via interviews or via fuzzy cognitive mapping or Bayesian belief network exercises in participatory workshops (e.g., Özesmi and Özesmi 2004, Langmead et al. 2009, Daw et al. 2015). Likewise, focus groups, interviews, or facilitated workshops can help clarify the problem context and identify key factors (social or ecological) and interactions to focus the investigation (e.g., Game et al. 2017, Guerrero and Wilson 2017). Increasing the awareness of the methodological tool kit available (Fig. A4.3 in Appendix 4) and how it can be used (Fig. 2) within a research team or project can help address this challenge.

Our results suggest that the application of theories is not associated with how well a study is integrated, with the exception of systems theory. This might be because many theories have particular disciplinary, e.g., social or ecological, roots, rather than emerging from a holistic perspective. However, new concepts, e. g., telecoupling (Liu et al. 2013), and methods, e.g., socialecological network analysis (Janssen et al. 2006, Bodin et al. 2016), continue to emerge that may offer new possibilities for integrating social and environmental aspects and the development and integration of theories in social-ecological research. Although promising, the insights that emerging interdisciplinary methods might bring to integrated SES research can only be revealed as empirical applications advance.

\section{Disciplinary integration}

Our results indicate that, in addition to environmental science and environmental studies, the ecology, biodiversity donservation, and urban studies disciplines play a key brokerage role in integrating other disciplines into social-ecological research. Perhaps this is because of the types of problems or questions being addressed, the more interdisciplinary nature, or the culture of researchers working within these disciplines. We caution that there are limitations in our approach to measuring disciplinary integration, which is based on the disciplinary classification used by the Web of Science, which assigns disciplines based on journals. Web of Science subject categories are among the most popular classification systems and are easily accessible (Waltman and van Eck 2012), enhancing our ability to undertake comparisons. However, journal-level classification systems have important limitations: multidisciplinary journals might include a wide range of fields, and thus, our approach might miss disciplines in which researchers are working but are not reflected by the journals in which they publish. More complex approaches, such as publication-level systems that classify individual publications into disciplinary clusters based on citations (Perianes-Rodriguez and Ruiz-Castillo 2017), have been proposed and could be adapted for further research. Nonetheless, the promise of integrated SES research will not be achievable unless disciplinary integration is pursued, and our results suggest several areas in which better integration is needed (Fig. 3).

There are, of course, numerous well-recognized challenges to interdisciplinary research, including funding challenges, distinct disciplinary methods and cultures, longer time requirements, and institutional constraints (Campbell 2005, Bromham et al. 2016). Greater disciplinary integration may be achieved by creating interdisciplinary teams, taking time to build trust and learn about different disciplines, ensuring that there is adequate funding and time, and designing projects with representatives from different disciplines (Christie 2011, Bennett et al. 2017). Inclusion of researchers from different disciplines will increase knowledge of different social and ecological considerations, thus increasing conceptual integration, and provide a more diverse methodological toolbox from which to draw, thus increasing methodological integration.

\section{Functional integration}

Our research showed that most SES research seeks to inform management actions in some way, whether it is through describing a system or through the testing of management alternatives; $70 \%$ of studies reviewed provided, even if general, recommendations. However, only $43 \%$ of the studies examined contained practical recommendations for management or policy.

Studies containing practical recommendations generally scored higher for the overall integration of social and ecological components than those that did not. This might be because more studies with an applied goal, e.g., research for a specific policy intervention, require integrated approaches, but it also suggests that the better integrated a study is, the more likely it is that researchers will be able to provide practical recommendations that are then more likely to create on-the-ground impacts. Nonetheless, this is an important finding for researchers interested in developing knowledge to support policy and practice and warrants further consideration of the most appropriate methodologies to support integration of different types of knowledge in SES research.

The importance of involving stakeholders in sustainability research that is intended to influence policy and practice is increasingly recognized (Lang et al. 2012, Wiek et al. 2012, Mauser et al. 2013). Literature on science-policy interfaces, knowledge coproduction, and boundary organizations highlights the importance of codesigned approaches to project planning that include shared problem definition among academics (natural and social scientists) and practitioners (from policy, community, business, and industry), integration of different types of knowledge, and engagement activities that enable the research to address challenges of practical relevance and promote stakeholder ownership (Young et al. 2014, Brondizio et al. 2016, Chapin et al. 2016, Turner et al. 2016). Our findings suggest that stakeholder involvement should be strategic and occur at appropriate stages of the research process, particularly in the design phase. This might be because, with appropriate design and facilitation, dialogue between scientists, policy makers, practitioners, and impacted stakeholders can improve knowledge exchange and learning, decision making, and research influence (Reyers et al. 2015, Nel et al. 2016), all critical components of improving the quality and impact of integrated research. Utilizing a broader knowledge base for study design can also facilitate a better description of the study system with its diverse social and natural components. Strategic involvement at key stages can also reduce the costs, e.g., time and resources, of involving stakeholders at all stages (Reid et al. 2016), support the design of relevant project objectives and research questions, enable the identification of practical recommendations that will be useful, and help capture the values and preferences that can reveal potential conflicting objectives and trade-offs between possible 
management solutions (Gregory and Keeney 1994). Early stakeholder analyses can help identify stakeholder groups that should be considered to facilitate engagement (e.g., Prell et al. 2009). Although participation of stakeholders within research processes is commonly proposed to improve the use of knowledge in policy or practice, to be effective these engagements require dedicated time and resources to support facilitation, mediation, and communication between different perspectives (Cash et al. 2006). Moreover, such engagements must be supported by a core ethic of trust, respect, and empathy and should not engage stakeholders in a tokenistic fashion that is purely about meeting research objectives without acknowledging the real-world implications for those engaged in the process (Reed et al. 2014).

\section{CONCLUSIONS}

Recommendations to increase integration and the potential applied impact of social-ecological systems research

This systematic review highlights significant work needed to achieve the promise and potential of integrated SES research. This is critical if we are to solve complex real-world sustainability problems. The results of our review, and their contextualization using literatures on conceptual, methodological, disciplinary, and functional integration, point to six clear recommendations for improving integration in future SES research projects:

1. Increase the interdisciplinary composition of research teams: Inclusion of both natural and social scientists, and researchers with diverse training, methodological, and analytical skills, from the beginning will improve the likelihood of integration throughout research projects. Where funding is a challenge, this may be achieved by building a network of colleagues from different backgrounds. Diverse disciplinary specialists provide distinct ways of looking at and solving environmental problems.

2. Involve stakeholders strategically in research projects: Undertaking stakeholder analyses early in the research process can inform stakeholder selection and help identify how and when they should be engaged. Stakeholder insights might be the most strategic and effective at project design stages and when identifying implications and recommendations. Stakeholder engagement cannot be tokenistic; it requires time and resources to ensure participation on equal footing, with respect for stakeholders' knowledge and contributions.

3. Use a diversity of tools, methods, and analysis: Studies that integrate a diverse set of methods, including both qualitative and quantitative methods, will be able to draw on the strengths and insights of each. In addition, emergent methodological approaches that are interdisciplinary in nature can help bridge the challenges that can exist when trying to integrate methods designed from different disciplinary perspectives.

4. Incorporate a more comprehensive set of social and ecological variables: To improve conceptual integration, we also identify a need to develop and draw from generic categorizations of different social and ecological variables in developing SES research projects. This will ensure that projects consider and prioritize important system elements in a more systematic fashion.
5. Consider bidirectional relationships: When trying to understand SES systems, the two-way interactions and feedbacks between social and ecological components need to be considered and studied.

6. Identify implications and articulate clear recommendations: Finally, improved integration based on points 1 to 5 should facilitate the identification of actionable recommendations. We urge SES researchers to identify the implications of research and provide clearly articulated recommendations, as they are critical for evidence-based policy and management decisions.

Although many of the suggestions are not particularly new, our research provides evidence that these actions are warranted and necessary to improve the process and outcomes of SES research. The urgency and complexity of contemporary environmental challenges requires that our SES research efforts are more strategically integrative to effectively address sustainability problems.

Responses to this article can be read online at: http://www.ecologyandsociety.org/issues/responses. php/10232

\section{Acknowledgments:}

We acknowledge the Australian Research Council Centre of Excellence for Environmental Decisions for funding and support. $N$. Carter was supported by Boise State University (NSF award IIA-1301792 from the NSF Idaho EPSCoR Program and the National Science Foundation). A. Nuno was supported by Defra Darwin Initiative.

\section{LITERATURE CITED}

Anthony, L. L., and D. T. Blumstein. 2000. Integrating behaviour into wildlife conservation: the multiple ways that behaviour can reduce $N_{\mathrm{e}}$. Biological Conservation 95:303-315. http://dx.doi. org/10.1016/S0006-3207(00)00037-9

Ban, N. C., M. Mills, J. Tam, C. C. Hicks, S. Klain, N. Stoeck1, M. C. Bottrill, J. Levine, R. L. Pressey, T. Satterfield, and K. M. A. Chan. 2013. A social-ecological approach to conservation planning: embedding social considerations. Frontiers in Ecology and the Environment 11:194-202. http://dx.doi.org/10.1890/110205

Bennett, N. J., J. Blythe, S. Tyler, and N. C. Ban. 2016. Communities and change in the anthropocene: understanding social-ecological vulnerability and planning adaptations to multiple interacting exposures. Regional Environmental Change 16:907-926. http://dx.doi.org/10.1007/s10113-015-0839-5

Bennett, N. J., R. Roth, S. C. Klain, K. M. A. Chan, D. A. Clark, G. Cullman, G. Epstein, M. P. Nelson, R. Stedman, T. L. Teel, R. E. W. Thomas, C. Wyborn, D. Curran, A. Greenberg, J. Sandlos, and D. Veríssimo. 2017. Mainstreaming the social sciences in conservation. Conservation Biology 31:56-66. http://dx.doi. org/10.1111/cobi.12788 
Berkes, F., J. Colding, and C. Folke. 2001. Linking socialecological systems. Cambridge University Press, Cambridge, UK.

Berkes, F., J. Colding, and C. Folke. 2003. Navigating socialecological systems: building resilience for complexity and change. Cambridge University Press, Cambridge, UK.

Biggs, R., S. R. Carpenter, and W. A. Brock. 2009. Turning back from the brink: detecting an impending regime shift in time to avert it. Proceedings of the National Academy of Sciences of the United States of America 106:826-831. http://dx.doi.org/10.1073/ pnas.0811729106

Binder, C. R., J. Hinkel, P. W. G. Bots, and C. Pahl-Wostl. 2013. Comparison of frameworks for analyzing social-ecological systems. Ecology and Society 18(4):26. http://dx.doi.org/10.5751/ ES-05551-180426

Bodin, Ö., G. Robins, R. R. J. McAllister, A. Guerrero, B. Crona, M. Tengö, and M. Lubell. 2016. Theorizing benefits and constraints in collaborative environmental governance: a transdisciplinary social-ecological network approach for empirical investigations. Ecology and Society 21(1):40. http://dx. doi.org/10.5751/ES-08368-210140

Bromham, L., R. Dinnage, and X. Hua. 2016. Interdisciplinary research has consistently lower funding success. Nature 534:684-687. http://dx.doi.org/10.1038/nature18315

Brondizio, E. S., E. Foufoula-Georgiou, S. Szabo, N. Vogt, Z. Sebesvari, F. G. Renaud, A. Newton, E. Anthony, A. V. Mansur, Z. Matthews, S. Hetrick, S. M. Costa, Z. Tessler, A. Tejedor, A. Longjas, and J. A. Dearing. 2016. Catalyzing action towards the sustainability of deltas. Current Opinion in Environmental Sustainability 19:182-194. http://dx.doi.org/10.1016/j.cosust.2016.05.001

Brown, R. R., A. Deletic, and T. H. F. Wong. 2015. Interdisciplinarity: how to catalyse collaboration. Nature 525:315-317. http://dx.doi.org/10.1038/525315a

Bunnefeld, N., E. Hoshino, and E. J. Milner-Gulland. 2011. Management strategy evaluation: a powerful tool for conservation? Trends in Ecology \& Evolution 26:441-447. http:// dx.doi.org/10.1016/i.tree.2011.05.003

Campbell, L. M. 2005. Overcoming obstacles to interdisciplinary research. Conservation Biology 19:574-577. http://dx.doi. org/10.1111/j.1523-1739.2005.00058.x

Carter, N. H., J. V. López-Bao, J. T. Bruskotter, M. Gore, G. Chapron, A. Johnson, Y. Epstein, M. Shrestha, J. Frank, O. Ohrens, and A. Treves. 2017. A conceptual framework for understanding illegal killing of large carnivores. Ambio 46:251-264. http://dx.doi.org/10.1007/s13280-016-0852-Z

Carter, N. H., B. K. Shrestha, J. B. Karki, N. M. B. Pradhan, and J. Liu. 2012. Coexistence between wildlife and humans at fine spatial scales. Proceedings of the National Academy of Sciences of the United States of America 109:15360-15365. http://dx.doi. org/10.1073/pnas.1210490109

Cash, D. W., J. C. Borck, and A. G. Patt. 2006. Countering the loading-dock approach to linking science and decision making. Science, Technology, \& Human Values 31:465-494. http://dx.doi. org/10.1177/0162243906287547
Chan, K. M. A., P. Balvanera, K. Benessaiah, M. Chapman, S. Díaz, E. Gómez-Baggethun, R. Gould, N. Hannahs, K. Jax, S. Klain, G. W. Luck, B. Martín-López, B. Muraca, B. Norton, K. Ott, U. Pascual, T. Satterfield, M. Tadaki, J. Taggart, and N. Turner. 2016. Opinion: why protect nature? Rethinking values and the environment. Proceedings of the National Academy of Sciences of the United States of America 113:1462-1465. http:// dx.doi.org/10.1073/pnas.1525002113

Chapin, F. S., III, C. N. Knapp, T. J. Brinkman, R. Bronen, and P. Cochran. 2016. Community-empowered adaptation for selfreliance. Current Opinion in Environmental Sustainability 19:67-75. http://dx.doi.org/10.1016/j.cosust.2015.12.008

Christie, P. 2011. Creating space for interdisciplinary marine and coastal research: five dilemmas and suggested resolutions. Environmental Conservation 38:172-186. http://dx.doi.org/10.1017/ $\underline{\text { S0376892911000129 }}$

Cinner, J. E. 2011. Social-ecological traps in reef fisheries. Global Environmental Change 21:835-839. http://dx.doi.org/10.1016/j. gloenvcha.2011.04.012

Cinner, J. E., C. Huchery, M. A. MacNeil, N. A. J. Graham, T. R. McClanahan, J. Maina, E. Maire, J. N. Kittinger, C. C. Hicks, C. Mora, E. H. Allison, S. D’Agata, A. Hoey, D. A. Feary, L. Crowder, I. D. Williams, M. Kulbicki, L. Vigliola, L. Wantiez, G. Edgar, R. D. Stuart-Smith, S. A. Sandin, A. L. Green, M. J. Hardt, M. Beger, A. Friedlander, S. J. Campbell, K. E. Holmes, S. K. Wilson, E. Brokovich, A. J. Brooks, J. J. Cruz-Motta, D. J. Booth, P. Chabanet, C. Gough, M. Tupper, S. C. A. Ferse, U. R. Sumaila, and D. Mouillot. 2016. Bright spots among the world's coral reefs. Nature 535:416-419. http://dx.doi.org/10.1038/nature18607

Daw, T. M., S. Coulthard, W. W. L. Cheung, K. Brown, C. Abunge, D. Galafassi, G. D. Peterson, T. R. McClanahan, J. O. Omukoto, and L. Munyi. 2015. Evaluating taboo trade-offs in ecosystems services and human well-being. Proceedings of the National Academy of Sciences of the United States of America 112:6949-6954. http://dx.doi.org/10.1073/pnas.1414900112

Finkbeiner, E. M., N. J. Bennett, T. H. Frawley, J. G. Mason, D. K. Briscoe, C. M. Brooks, C. A. Ng, R. Ourens, K. Seto, S. S. Swanson, J. Urteaga, and L. B. Crowder. 2017. Reconstructing overfishing: moving beyond Malthus for equitable and effective solutions. Fish and Fisheries 18:1180-1191. http://dx.doi. org/10.1111/faf.12245

Fischer, J., T. A. Gardner, E. M. Bennett, P. Balvanera, R. Biggs, S. Carpenter, T. Daw, C. Folke, R. Hill, T. P. Hughes, T. Luthe, M. Maass, M. Meacham, A. V. Norström, G. Peterson, C. Queiroz, R. Seppelt, M. Spierenburg, and J. Tenhunen. 2015. Advancing sustainability through mainstreaming a socialecological systems perspective. Current Opinion in Environmental Sustainability 14:144-149. http://dx.doi.org/10.1016/j.cosust.2015.06.002

Freeman, L. C. 1977. Set of measures of centrality based on betweenness. Sociometry 40:35-41. http://dx.doi.org/10.2307/3033543

Game, E. T., L. L. Bremer, A. Calvache, P. H. Moreno, A. Vargas, B. Rivera, and L. M. Rodriguez. 2017. Fuzzy models to inform social and environmental indicator selection for conservation impact monitoring. Conservation Letters 11:e12338. http://dx. doi.org/10.1111/conl.12338 
Gregory, R., and R. L. Keeney. 1994. Creating policy alternatives using stakeholder values. Management Science 40:1035-1048. http://dx.doi.org/10.1287/mnsc.40.8.1035

Guerrero, A. M., and K. A. Wilson. 2017. Using a socialecological framework to inform the implementation of conservation plans. Conservation Biology 31:290-301. http://dx. doi.org/10.1111/cobi.12832

Gunderson, L. H., and C. S. Holling. 2002. Panarchy: understanding transformations in human and natural systems. Island, Washington, D.C., USA.

Hicks, C. C., L. B. Crowder, N. A. J. Graham, J. N. Kittinger, and E. L. Cornu. 2016a. Social drivers forewarn of marine regime shifts. Frontiers in Ecology and the Environment 14:252-260. http:// dx.doi.org/10.1002/fee.1284

Hicks, C. C., C. Fitzsimmons, and N. V. C. Polunin. 2010. Interdisciplinarity in the environmental sciences: barriers and frontiers. Environmental Conservation 37:464-477. http://dx.doi. org/10.1017/S0376892910000822

Hicks, C. C., A. Levine, A. Agrawal, X. Basurto, S. J. Breslow, C. Carothers, S. Charnley, S. Coulthard, N. Dolsak, J. Donatuto, C. Garcia-Quijano, M. B. Mascia, K. Norman, M. R. Poe, T. Satterfield, K. St. Martin, and P. S. Levin. 2016b. Engage key social concepts for sustainability. Science 352:38-40. http://dx.doi. org/10.1126/science.aad4977

Hoban, S. M., H. C. Hauffe, S. Pérez-Espona, J. W. Arntzen, G. Bertorelle, J. Bryja, K. Frith, O. E. Gaggiotti, P. Galbusera, J. A. Godoy, A. R. Hoelzel, R. A. Nichols, C. R. Primmer, I.-R. Russo, G. Segelbacher, H. R. Siegismund, M. Sihvonen, C. Vernesi, C. Vilà, and M. W. Bruford. 2013. Bringing genetic diversity to the forefront of conservation policy and management. Conservation Genetics Resources 5:593-598. http://dx.doi.org/10.1007/s12686-013-9859叉

Janssen, M. A., Ö. Bodin, J. M. Anderies, T. Elmqvist, H. Ernstson, R. R. J. McAllister, P. Olsson, and P. Ryan. 2006. Toward a network perspective on the resilience of socialecological systems. Ecology and Society 11(1):15. http://dx.doi. org/10.5751/ES-01462-110115

Kajikawa, Y., F. Tacoa, and K. Yamaguchi. 2014. Sustainability science: the changing landscape of sustainability research. Sustainability Science 9:431-438. http://dx.doi.org/10.1007/ s11625-014-0244-X

Knight, A. T., R. M. Cowling, and B. M. Campbell. 2006. An operational model for implementing conservation action. Conservation Biology 20:408-419. http://dx.doi.org/10.1111/ j.1523-1739.2006.00305.x

Krempel, L. 2011. Network visualization. Pages 558-577 in J. Scott and P. J. Carrington, editors. The SAGE handbook of social network analysis. SAGE, London, UK.

Lang, D. J., A. Wiek, M. Bergmann, M. Stauffacher, P. Martens, P. Moll, M. Swilling, and C. J. Thomas. 2012. Transdisciplinary research in sustainability science: practice, principles, and challenges. Sustainability Science 7:25-43. http://dx.doi. org/10.1007/s11625-011-0149-X

Langmead, O., A. McQuatters-Gollop, L. D. Mee, J. Friedrich, A. J. Gilbert, M.-T. Gomoiu, E. L. Jackson, S. Knudsen, G.
Minicheva, and V. Todorova. 2009. Recovery or decline of the northwestern Black Sea: a societal choice revealed by socioecological modelling. Ecological Modelling 220:2927-2939. http:// dx.doi.org/10.1016/j.ecolmodel.2008.09.011

Larrosa, C., L. R. Carrasco, and E. J. Milner-Gulland. 2016. Unintended feedbacks: challenges and opportunities for improving conservation effectiveness. Conservation Letters 9:316-326. http://dx.doi.org/10.1111/conl.12240

Levin, S., T. Xepapadeas, A.-S. Crépin, J. Norberg, A. de Zeeuw, C. Folke, T. Hughes, K. Arrow, S. Barrett, G. Daily, P. Ehrlich, N. Kautsky, K.-G. Mäler, S. Polasky, M. Troell, J. R. Vincent, and B. Walker. 2013. Social-ecological systems as complex adaptive systems: modeling and policy implications. Environment and Development Economics 18:111-132. http://dx.doi.org/10.1017/ $\underline{\mathrm{S} 1355770 \mathrm{X} 12000460}$

Leydesdorff, L. 2007. Betweenness centrality as an indicator of the interdisciplinarity of scientific journals. Journal of the American Society for Information Science and Technology 58:1303-1319. http://dx.doi.org/10.1002/asi.20614

Liu, J., T. Dietz, S. R. Carpenter, M. Alberti, C. Folke, E. Moran, A. N. Pell, P. Deadman, T. Kratz, J. Lubchenco, E. Ostrom, Z. Ouyang, W. Provencher, C. L. Redman, S. H. Schneider, and W. W. Taylor. 2007. Complexity of coupled human and natural systems. Science 317:1513-1516. http://dx.doi.org/10.1126/ science. 1144004

Liu, J., V. Hull, M. Batistella, R. DeFries, T. Dietz, F. Fu, T. W. Hertel, R. C. Izaurralde, E. F. Lambin, S. Li, L. A. Martinelli, W. J. McConnell, E. F. Moran, R. Naylor, Z. Ouyang, K. R. Polenske, A. Reenberg, G. de Miranda Rocha, C. S. Simmons, P. H. Verburg, P. M. Vitousek, F. Zhang, and C. Zhu. 2013. Framing sustainability in a telecoupled world. Ecology and Society 18 (2):26. http://dx.doi.org/10.5751/ES-05873-180226

Liu, J., H. Mooney, V. Hull, S. J. Davis, J. Gaskell, T. Hertel, J. Lubchenco, K. C. Seto, P. Gleick, C. Kremen, and S. Li. 2015. Systems integration for global sustainability. Science 347:12588832. http://dx.doi.org/10.1126/science.1258832

Mace, G. M. 2014. Whose conservation? Science 345:1558-1560. http://dx.doi.org/10.1126/science.1254704

Manfredo, M. J., J. J.Vaske, A. Rechkemmer, and E. A. Duke. 2014. Understanding society and natural resources: forging new strands of integration across the social sciences. Springer, Dordrecht, the Netherlands. http://dx.doi.org/10.1007/978-94-017-8959-2

Mascia, M. B., J. P. Brosius, T. A. Dobson, B. C. Forbes, L. Horowitz, M. A. McKean, and N. J. Turner. 2003. Conservation and the social sciences. Conservation Biology 17:649-650. http:// dx.doi.org/10.1046/j.1523-1739.2003.01738.x

Mauser, W., G. Klepper, M. Rice, B. S. Schmalzbauer, H. Hackmann, R. Leemans, and H. Moore. 2013. Transdisciplinary global change research: the co-creation of knowledge for sustainability. Current Opinion in Environmental Sustainability 5:420-431. http://dx.doi.org/10.1016/j.cosust.2013.07.001

Milner-Gulland, E. J. 2012. Interactions between human behaviour and ecological systems. Philosophical Transactions of the Royal Society B: Biological Sciences 367:270-278. http://dx. doi.org/10.1098/rstb.2011.0175 
Nel, J. L., D. J. Roux, A. Driver, L. Hill, A. C. Maherry, K. Snaddon, C. R. Petersen, L. B. Smith-Adao, H. Van Deventer, and B. Reyers. 2016. Knowledge co-production and boundary work to promote implementation of conservation plans. Conservation Biology 30:176-188. http://dx.doi.org/10.1111/ cobi. 12560

Ostrom, E. 2007. A diagnostic approach for going beyond panaceas. Proceedings of the National Academy of Sciences of the United States of America 104:15181-15187. http://dx.doi. org/10.1073/pnas.0702288104

Özesmi, U., and S. L. Özesmi. 2004. Ecological models based on people's knowledge: a multi-step fuzzy cognitive mapping approach. Ecological Modelling 176:43-64. http://dx.doi. org/10.1016/j.ecolmodel.2003.10.027

Perianes-Rodriguez, A., and J. Ruiz-Castillo. 2017. A comparison of the Web of Science and publication-level classification systems of science. Journal of Informetrics 11(1):32-45. http://dx.doi. org/10.1016/j.joi.2016.10.007

Pollnac, R., P. Christie, J. E. Cinner, T. Dalton, T. M. Daw, G. E. Forrester, N. A. J. Graham, and T. R. McClanahan. 2010. Marine reserves as linked social-ecological systems. Proceedings of the National Academy of Sciences of the United States of America 107:18262-18265. http://dx.doi.org/10.1073/pnas.0908266107

Prell, C., K. Hubacek, and M. Reed. 2009. Stakeholder analysis and social network analysis in natural resource management. Society \& Natural Resources 22:501-518. http://dx.doi. org/10.1080/08941920802199202

Reed, M. S. 2008. Stakeholder participation for environmental management: a literature review. Biological Conservation 141:2417-2431. http://dx.doi.org/10.1016/j.biocon.2008.07.014

Reed, M. S., L. C. Stringer, I. Fazey, A. C. Evely, and J. H. J. Kruijsen. 2014. Five principles for the practice of knowledge exchange in environmental management. Journal of Environmental Management 146:337-345. http://dx.doi.org/10.1016/j.

jenvman.2014.07.021

Reid, R. S., D. Nkedianye, M. Y. Said, D. Kaelo, M. Neselle, O. Makui, L. Onetu, S. Kiruswa, N. O. Kamuaro, P. Kristjanson, J. Ogutu, S. B. BurnSilver, M. J. Goldman, R. B. Boone, K. A. Galvin, N. M. Dickson, and W. C. Clark. 2016. Evolution of models to support community and policy action with science: balancing pastoral livelihoods and wildlife conservation in savannas of East Africa. Proceedings of the National Academy of Sciences of the United States of America 113:4579-4584. http:// dx.doi.org/10.1073/pnas.0900313106

Reyers, B., R. Biggs, G. S. Cumming, T. Elmqvist, A. P. Hejnowicz, and S. Polasky. 2013. Getting the measure of ecosystem services: a social-ecological approach. Frontiers in Ecology and the Environment 11:268-273. http://dx.doi.org/10.1890/120144

Reyers, B., J. L. Nel, P. J. O'Farrell, N. Sitas, and D. C. Nel. 2015. Navigating complexity through knowledge coproduction: mainstreaming ecosystem services into disaster risk reduction. Proceedings of the National Academy of Sciences of the United States of America 112:7362-7368. http://dx.doi.org/10.1073/ pnas. 1414374112
Rissman, A. R., and S. Gillon. 2017. Where are ecology and biodiversity in social-ecological systems research? A review of research methods and applied recommendations. Conservation Letters 10:86-93. http://dx.doi.org/10.1111/conl.12250

Schlüter, M., R. R. J. McAllister, R. Arlinghaus, N. Bunnefeld, K. Eisenack, F. Hölker, E. J. Milner-Gulland, B. Müller, E. Nicholson, M. Quaas, and M. Stöven. 2012. New horizons for managing the environment: a review of coupled social-ecological systems modeling. Natural Resource Modeling 25:219-272. http:// dx.doi.org/10.1111/j.1939-7445.2011.00108.x

Svarstad, H., L. K. Petersen, D. Rothman, H. Siepel, and F. Wätzold. 2008. Discursive biases of the environmental research framework DPSIR. Land Use Policy 25:116-125. http://dx.doi. org/10.1016/j.landusepol.2007.03.005

Turner, B. L., II, K. J. Esler, P. Bridgewater, J. Tewksbury, N. Sitas, B. Abrahams, F. S. Chapin III, R. R. Chowdhury, P. Christie, S. Diaz, P. Firth, C. N. Knapp, J. Kramer, R. Leemans, M. Palmer, D. Pietri, J. Pittman, J. Sarukhán, R. Shackleton, R. Seidler, B. van Wilgen, and H. Mooney. 2016. Socio-environmental systems (SES) research: what have we learned and how can we use this information in future research programs. Current Opinion in Environmental Sustainability 19:160-168. http://dx.doi.org/10.1016/ j.cosust.2016.04.001

Van Noorden, R. 2015. Interdisciplinary research by the numbers. Nature 525:306-307.

Waltman, L., and N. J. van Eck. 2012. A new methodology for constructing a publication-level classification system of science. Journal of the American Society for Information Science and Technology 63(12):2378-2392. http://dx.doi.org/10.1002/asi.22748

Wiek, A., F. Farioli, K. Fukushi, and M. Yarime. 2012. Sustainability science: bridging the gap between science and society. Sustainability Science 7(S1):1-4. http://dx.doi.org/10.1007/ s11625-011-0154-0

Young, J. C., K. A. Waylen, S. Sarkki, S. Albon, I. Bainbridge, E. Balian, J. Davidson, D. Edwards, R. Fairley, C. Margerison, D. McCracken, R. Owen, C. P. Quine, C. Stewart-Roper, D. Thompson, R. Tinch, S. Van den Hove, and A. Watt. 2014. Improving the science-policy dialogue to meet the challenges of biodiversity conservation: having conversations rather than talking at one-another. Biodiversity and Conservation 23:387-404. http://dx.doi.org/10.1007/s10531-013-0607-0 
Appendix 1. Social-ecological research over time

To examine if the increase in number of social-environmental papers over time is simply due to general increase in number of publications (based on 700 abstracts we classified as "socialecological"), this was compared to number of publications published in the same time period in Web of Science's research areas "Environmental Sciences \& Ecology" and "Biodiversity Conservation".

When comparing the fit of linear and exponential models to the data, we found that, while the number of "Environmental Sciences \& Ecology" and "Biodiversity Conservation" publications over time is best explained by a linear model (i.e. based on AIC), the number of social-ecological publications over the same time period is best explained by an exponential model. This suggests a different growth trajectory type for social-ecological publications, which have increased considerably in the past years and are likely to keep increasing in the near future.

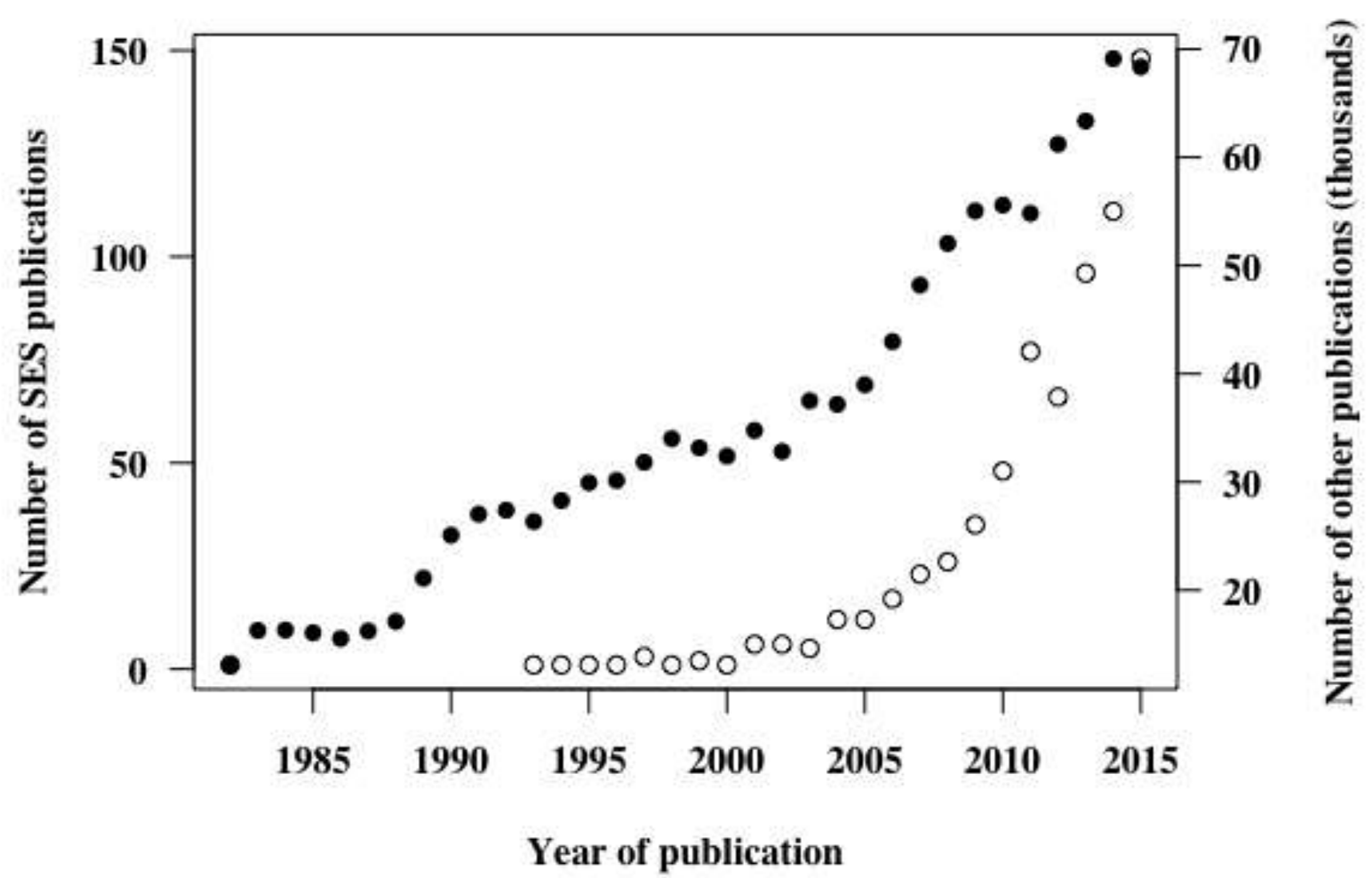

Fig. A1.1. Frequency of social-ecological (SES; o) and other $(\bullet)$ papers published over time. 
Appendix 2. Review phase 1 -Web of Science search criteria

We were interested in scientific articles or reviews published in English in the research areas of "Environmental Sciences \& Ecology" or "Biodiversity Conservation" that included keywords reflecting multiple approaches to social-ecological (also called human-environment or human-nature) research.

The following criteria were thus used to search papers potentially fitting our four pre-defined criteria:

- $\quad \mathrm{ts}=($ "soci*-ecological" or "human-environment" or "human-* conflict" or "human-* interaction*" or "soci*-environmental" or "SES" or "social-biophysical") AND

- $\mathrm{ts}=$ (ecosystem* ${ }^{*}$ or ecological or biophysical or biodiversity or fisher* or agricultur* or forestry) AND

- $\quad$ ts=(framework* or tool* or model* or applied or "decision-support system" or method*) AND

- $\quad \mathrm{su}=($ "Environmental Sciences \& Ecology" or "Biodiversity \& Conservation")) AND

- LANGUAGE: (English)

- Refined by: DOCUMENT TYPES: ( ARTICLE OR REVIEW )

\section{Summary of papers excluded during abstract review (Phase 1)}

At the search date $\left(18^{\text {th }}\right.$ November 2015), searching Web of Science with the set of criteria defined in (B) resulted in 1760 papers. Taking into account those criteria, after reading their abstracts (done by AG and AN), the following amount of papers were excluded (i.e. not moved to following phase) because:

- $109(6.2 \%)$ papers were not environmental related;

- $306(17.4 \%)$ papers described general environmental issues (e.g. PES);

- 118 (6.7\%) papers were reviews.

- $442(25.1 \%)$ papers had mainly social focus (e.g. focused on attitudes or governance issues without ecological factors);

- 85 (4.8\%) papers had mainly ecological focus (e.g. focused on animal abundance without social factors).

These papers were excluded from further analysis. Because some of the abstracts did not provide enough information to adequately establish if all of the above criteria were met, some screening questions were included in the next phase of the review (Phase 2 - see Appendix 3).

A subset of all relevant studies $(n=120)$ was selected for the review because of the logistical constraints faced by the author team, and because the focus of the study was on broad patterns and trends rather than capturing specific details of individual studies. 
Appendix 3. Review phase 2 - online survey questions

Review questions relevant to the analysis and results presented in manuscript:

1. Does the paper include both social and ecological aspects?

Please note that the inclusion of both social and ecological aspect was a key criteria when selecting papers for this review. Please double check the paper carefully before answering this question.

Yes

No

2. How is the interaction between social and ecological aspects considered?

Unidirectional (the interaction captured/considered is from the ecological to the social system, or vice-versa, but not both)

Bidirectional (both types of interactions are captured/considered i.e. from the ecological to the social system, and vice-versa)

N/A

3. What is the value orientation behind the application of the approach?

Conceptualisation is from an anthropocentric perspective (defines the ecological system based on its utility for humans)

$\square$ Conceptualisation is from an ecocentric perspective (defines the ecological system based on its internal functioning)

$\square$ Conceptualisation is from an relational perspective (defines the ecological systems based on how humans relate to it - pertains to all manner of relationships between people and nature -see picture below)

4a. What types of social variables are included?

Tick all that apply

Demographic (e.g. gender, educational level, location, ethnicity, race, family size, education, income and occupation)

$\square$ Economic (e.g. population, poverty rate, available resources, investment, costs/payments, profits, gross domestic product, employment indicators, inflation rates)

Politics or power

Governance (laws and policies, rules, institutions, procedures)

Management (resources, professionals, plans and actions taken to manage a resource)

Wellbeing

Infrastructure (physical structures and facilities)

Management systems (policies, processes and procedures of an entity)

Land use / resource use

Social relations/interactions/processes (e.g. social capital, collaboration, social movements, social learning)

Psychosocial constructs (e.g. norms, values, attitudes, beliefs, preferences)

Cultural aspects

Historical accounts

Behavioural (e.g. actions/decisions of individual(s) that have an effect on the ecological systems) 
Experiences (e.g. human experiences of the environment)

Other (please specify)

4b. What types of ecological variables are included? (empirical papers only) Tick all that apply

$\mathrm{n} / \mathrm{a}$

Ecosystem services (i.e. provisioning - food, raw materials, fresh water, medicinal resources; regulating - climate and air quality, carbon sequestration, moderation of extreme events, waste water treatment ; cultural - spiritual, recreation, tourism, education, aesthetic appreciation and inspiration for culture and art)

Biophysical aspects (e.g. habitat type/land cover type, climatic variables)

Biodiversity aspects (e.g. richness, distribution, abundance, functional diversity, phylogenetic diversity)

Ecological processes (e.g. Ecological functions - erosion control, soil fertility, pollination, biological control, nutrient cycles, energy transfer, community dynamics)

Geomorphological processes (e.g. erosion, weathering)

Evolutionary aspects (e.g. life-history traits)

Genetics (e.g. phenotypic traits, fitness)

Animal behaviour (e.g. how animals interact with each other, with their environment and with other living beings including humans)

Other (please specify)

5a. Does the paper involve a tool, method, model or conceptual framework for integrating social with ecological aspects?

Yes

No

Conceptual framework: Presents and explains and organises concepts and terms that may be used to construct the kinds of causal explanations expected of a theory. It can be an existing or a new framework.

Theory: posits specific causal relationships among core variables.

Model: Detailed manifestation of the functional relationships among variables important in a particular setting (different models can be used to represent different aspects of a given theory).

Tools and methods: instruments to help us undertake research.

5b. Please select the category that best describes the tool, method, model or framework used to integrate social with ecological aspects

Note: if the paper integrates more than one tool/method/framework please choose all that apply. Under "Other" you can include more information about your selection.

Agent-based modelling

Bayesian Belief Network (BBN)

Behavioural economics

Bio-economic modelling

Collection/comparison/combination of social and ecological data 
Conceptual models (e.g. mental models, casual-loop diagrams, cognitive maps, fuzzy maps/models)

Dynamic modelling

$\square$ Decision support tool/approach (e.g. structured decision making, modelling + expert elicitation, decision tree analysis, multi- criteria decision analysis)

$\square$ Descriptive approaches (case study analysis, historical analysis)

Driver-Pressure-State-Impact-Response (DPSIR)

Ecosystem services framework

Game-theoretic modelling

Human appropriation of net primary production

Integrated index (please provide further info under "Other")

Integrated modelling (e.g. ecological modelling with agent-based modelling, population model with human/social parameters/scenarios)

Institutional Analysis and Development (IAD)

Institutional design principles (Ostrom)

Institutional fit (social-ecological fit)

Long-term social-ecological research

Management Strategy Evaluation

Multi-agent modelling

Participatory approaches (e.g. participatory impact assessment, cognitive mapping, community values mapping, participatory modelling, participatory scenario building, role-playing games, participatory GIS, PRA)

Pressure-state-response (PSR)

Qualitative models

Resilience framework/Adaptive capacity/Panarchy/Adaptive cycle

Scenario assessment/analysis

Simulation modelling

System modelling

Social-ecological experiments

Social-ecological systems framework (e.g. Ostrom's or other - please clarify under "Other")

Social-ecological networks

Spatial integration of social and ecological data

Statistical analysis of social and ecological data

Sustainable livelihoods

Sustainability assessment

Telecoupling

Vulnerability assessment

Other (please specify - if more than one please separate answers with a comma)

5c. Please tick on the particular theory (or theories) driving the approach?

N/A. There doesn't seem to be a specific theory driving the approach

Resilience theory

Common Pool Resource (CPR) theory

Game theory

Panarchy

Adaptive cycle theory

Systems theory

Complexity theory 


\section{Decision theory}

Other (please specify)

5d. How is the framework, tool, model, or method being (or proposed to be) used?

Tick all that apply

to describe/understand the system (e.g. understand elements, relationships, problems or gaps)

to identify/explore/test management alternatives/strategies or policy evaluation

to monitor and/or evaluate policies (efficacy)

to identify priorities or "optimal" solutions (finding the best answer for a specific problem)

to identify desired way forward/direction/predict future change (model future states)

to describe historical changes

to test hypothesis

to build theories

to build tools or create methods

to engage stakeholders

other (please specify)

6. Is the analysis conducted qualitative, quantitative or both?

Qualitative

Quantitative

Both

N/A

9a. Does the paper mention any of the following stakeholder types as having been involved as a collaborator in the research process?

Resource users

Scientific experts

Cultural groups

Community groups

Industry groups

NGOs

Government organisations

Private companies

General public

No one involved (none are mentioned)

Unable to tell (seems that some stakeholder types were involved but it is not clear who)

N/A (conceptual paper)

Other (please specify)

9b. For each stakeholder type indicated in the previous question, at what stages of the study were they involved? (problem identification, study design, data collection, analysis/assessment, delivery of outputs) 


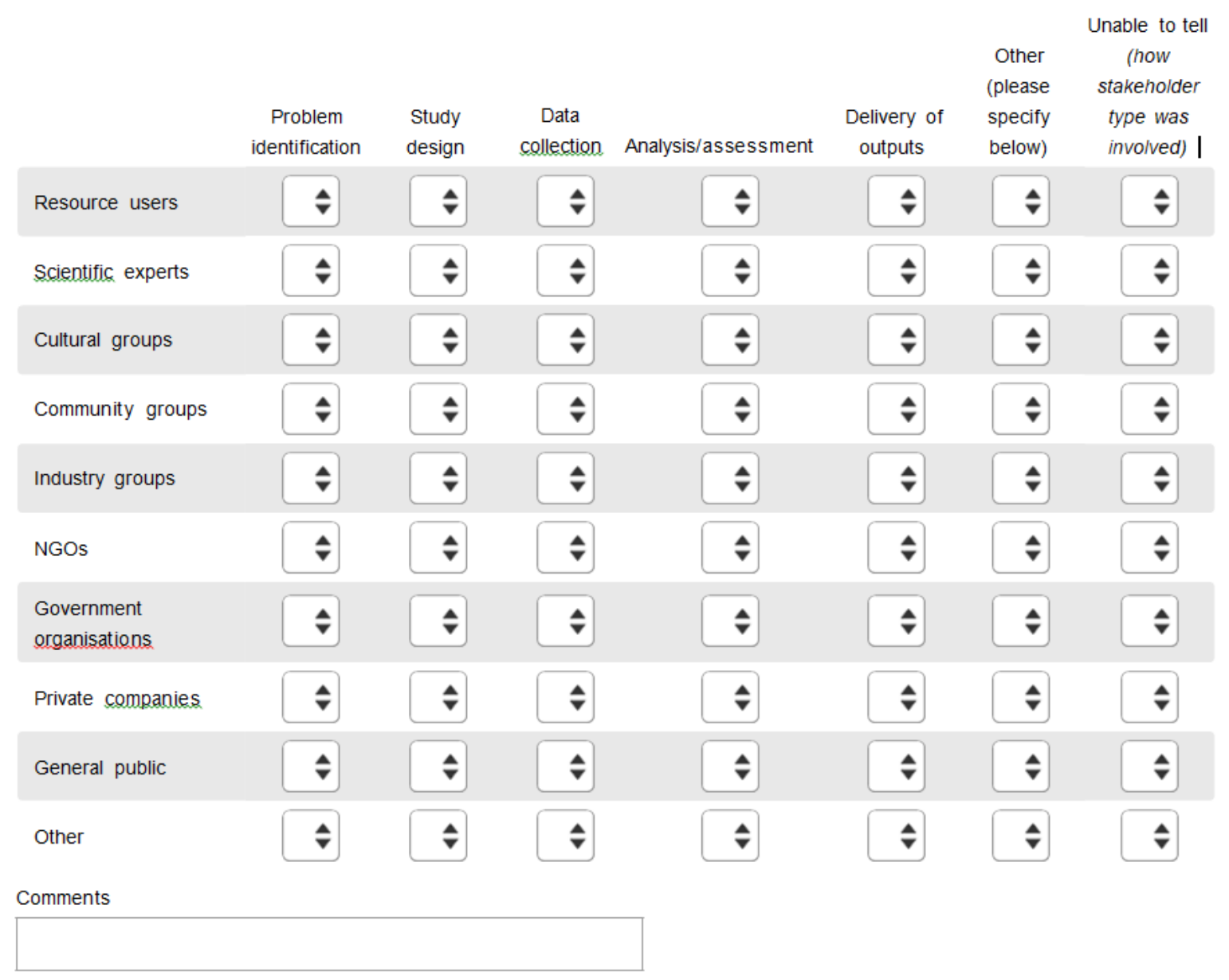

10. To what extent does the paper/research lead to practical recommendations? (1: No recommendations, 5: Provides an extensive and clear list of recommendations for policy or practice)

11. On a scale of 1 to 5 , to what extent would you say that social and ecological aspects are integrated? (Where 1 is minimal integration and 5 is a great amount of integration)

Minimal integration : focus is on either the social/human or the natural/ecological system, and only one (or a few) variables/components of the other system are considered

A great amount of integration: Feedbacks between social and ecological components are explicitly accounted for/considered or multiple processes involving both social and ecological variables are considered at the same time

Other questions:

Is it an empirical or conceptual* paper?

Empirical only

Conceptual only

Empirical and conceptual 
Neither. It is a review or other type of paper

Conceptual paper: Presents and explains and organizes concepts (abstract descriptions of phenomena) together. It can be a new conceptualization, an existing conceptualization, or an adaptation of an existing conceptualization.

Empirical paper: reports the results of a study that uses actual data derived from observation or experimentation (this includes data derived from expert opinion or local knowledge).

A paper can be considered to be "empirical and conceptual" when the conceptual framework that is applied is first explained in detail (these type of papers usually have a diagram, but not all do).

What type of problem or problems are being addressed through the application (or proposed application) of the approach?

Tick all that apply

Residential and commercial development related problems or conflicts (including tourism related)

Agriculture and aquaculture related problems or conflicts

Energy production and mining related problems or conflicts

Transportation and associated related problem or conflicts

Biological resource use (e.g. hunting and collecting terrestrial animals, logging and wood harvesting, fishing aquatic resources)

$\square$ Human activities that may alter, destroy and disturb habitats and species associated with nonconsumptive uses of biological resources (including recreational, war, civil unrest)

$\square$ Natural systems modifications (often to improve human welfare e.g. fire suppression or increase, change in water flow patterns)

$\square$ Invasive and other problematic species and genes (e.g. invasive non-native species, problematic native species, introduced genetic material)

Pollution (e.g. agricultural and forestry effluents, domestic sewage and urban waste water, industrial and military effluents, garbage and solid waste, air-borne pollutants)

Geological events (e.g. volcanoes, earthquakes, avalanches or landslides)

Climate change and severe weather (habitat shifting and alteration, droughts, temperature extremes, storms and flooding)

$\square$ Community development issues (e.g. educational, cultural, economic, social and environmental wellbeing of communities)

$\square$ Other (please specify) 
Appendix 4. Detailed results

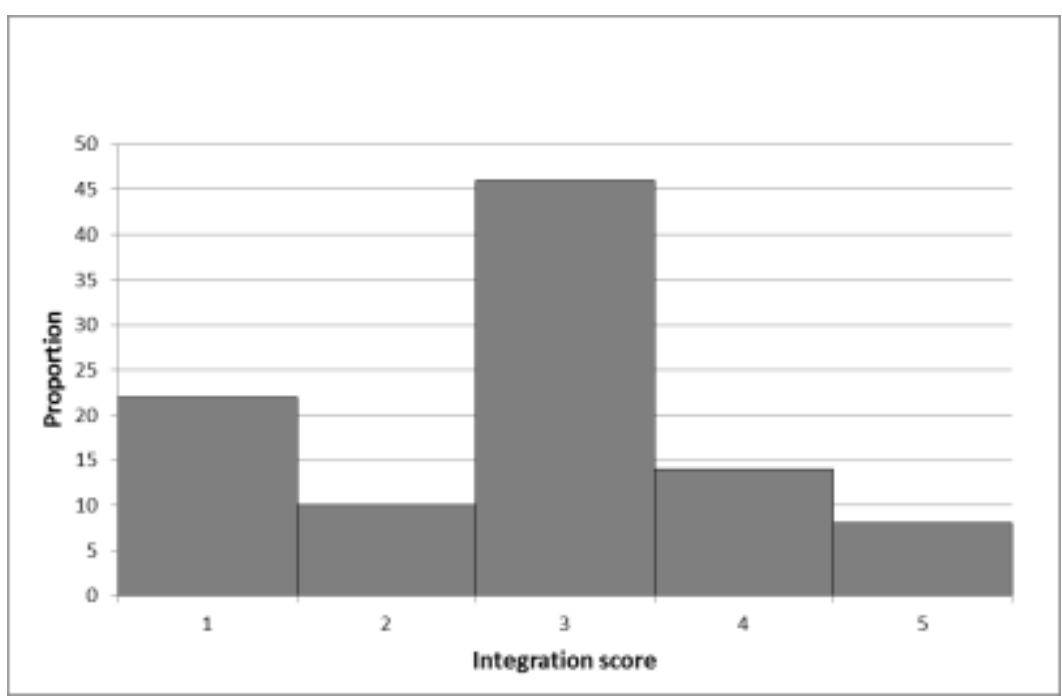

Fig. A4.1Relative frequency distribution of integration score $(n=101)$. Likert scale from 1 (minimal integration) to 5 (very well integrated).

Table A4.1 Representation of different types of social and environmental variables in empirical papers and betweenness centrality scores. High betweenness centrality scores are highlighted in grey, indicating the variables that are more commonly integrated with other variables.

\begin{tabular}{|c|c|c|c|}
\hline Type of variable & $\begin{array}{l}\text { No. of } \\
\text { papers }\end{array}$ & $\begin{array}{c}\% \\
(\mathbf{n}=\mathbf{1 0 1})\end{array}$ & $\begin{array}{l}\text { Betweenness } \\
\text { centrality }\end{array}$ \\
\hline Land use or resource use & 75 & 74.3 & 6.340 \\
\hline Biophysical aspects & 72 & 71.3 & 6.340 \\
\hline $\begin{array}{l}\text { Economic (e.g. population, poverty rate, available } \\
\text { resources, investment, costs/payments, profits, gross } \\
\text { domestic product, employment indicators, inflation rates) }\end{array}$ & 62 & 61.4 & 3.174 \\
\hline Ecosystem services & 52 & 51.5 & 0.959 \\
\hline $\begin{array}{l}\text { Management (resources, professionals, plans and actions } \\
\text { taken to manage a resource) and } \\
\text { Management systems (policies, processes and procedures } \\
\text { of an entity) }\end{array}$ & 52 & 51.5 & 3.793 \\
\hline Biodiversity aspects & 49 & 48.5 & 6.340 \\
\hline $\begin{array}{l}\text { Demographic (e.g. gender, educational level, location, } \\
\text { ethnicity, race, family size, education, income and } \\
\text { occupation) }\end{array}$ & 48 & 47.5 & 6.340 \\
\hline $\begin{array}{l}\text { Governance (e.g. laws and policies, rules, institutions, } \\
\text { procedures) }\end{array}$ & 44 & 43.6 & 3.793 \\
\hline Ecological processes & 42 & 41.6 & 0.614 \\
\hline $\begin{array}{l}\text { Behavioural (e.g., actions/decisions of individual(s) that } \\
\text { have an effect on the ecological systems) }\end{array}$ & 33 & 32.7 & 3.174 \\
\hline Infrastructure (physical structures and facilities) & 32 & 31.7 & 0.959 \\
\hline $\begin{array}{l}\text { Social relations/interactions/processes (e.g. social capital, } \\
\text { collaboration, social movements, social learning) }\end{array}$ & 27 & 26.7 & 2.238 \\
\hline $\begin{array}{l}\text { Psychosocial constructs (e.g. norms, values, attitudes, } \\
\text { beliefs, preferences) }\end{array}$ & 25 & 24.8 & 2.482 \\
\hline Historical accounts & 22 & 21.8 & 0.959 \\
\hline
\end{tabular}


Cultural aspects

Experiences

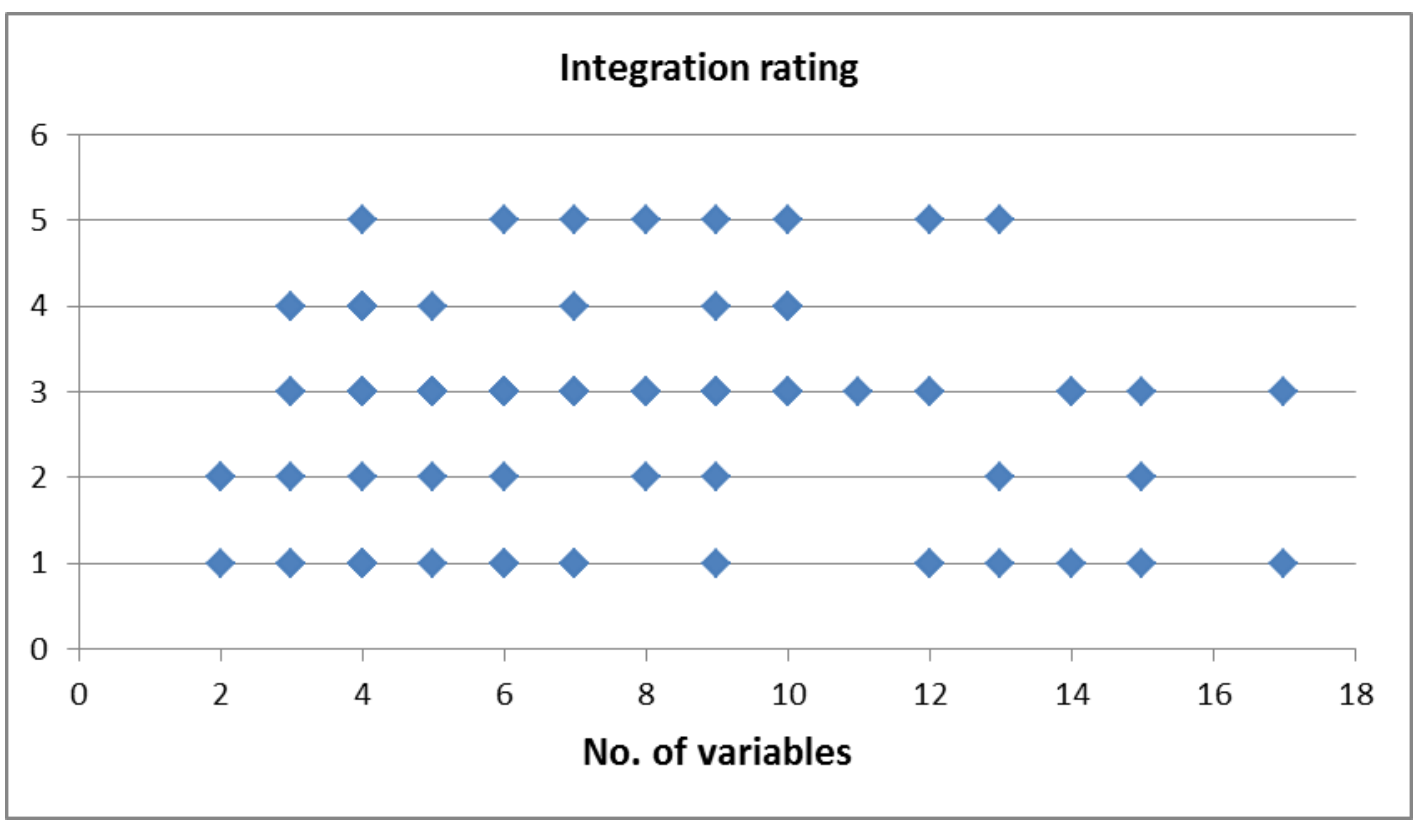

Fig. A4.2 Scatter plot indicating a lack of association between number of variables used in empirical studies and level of social-ecological integration. Some of the data points are overlaid on top of others because more than one study could have used the same amount of variables and rated equally for integration. 


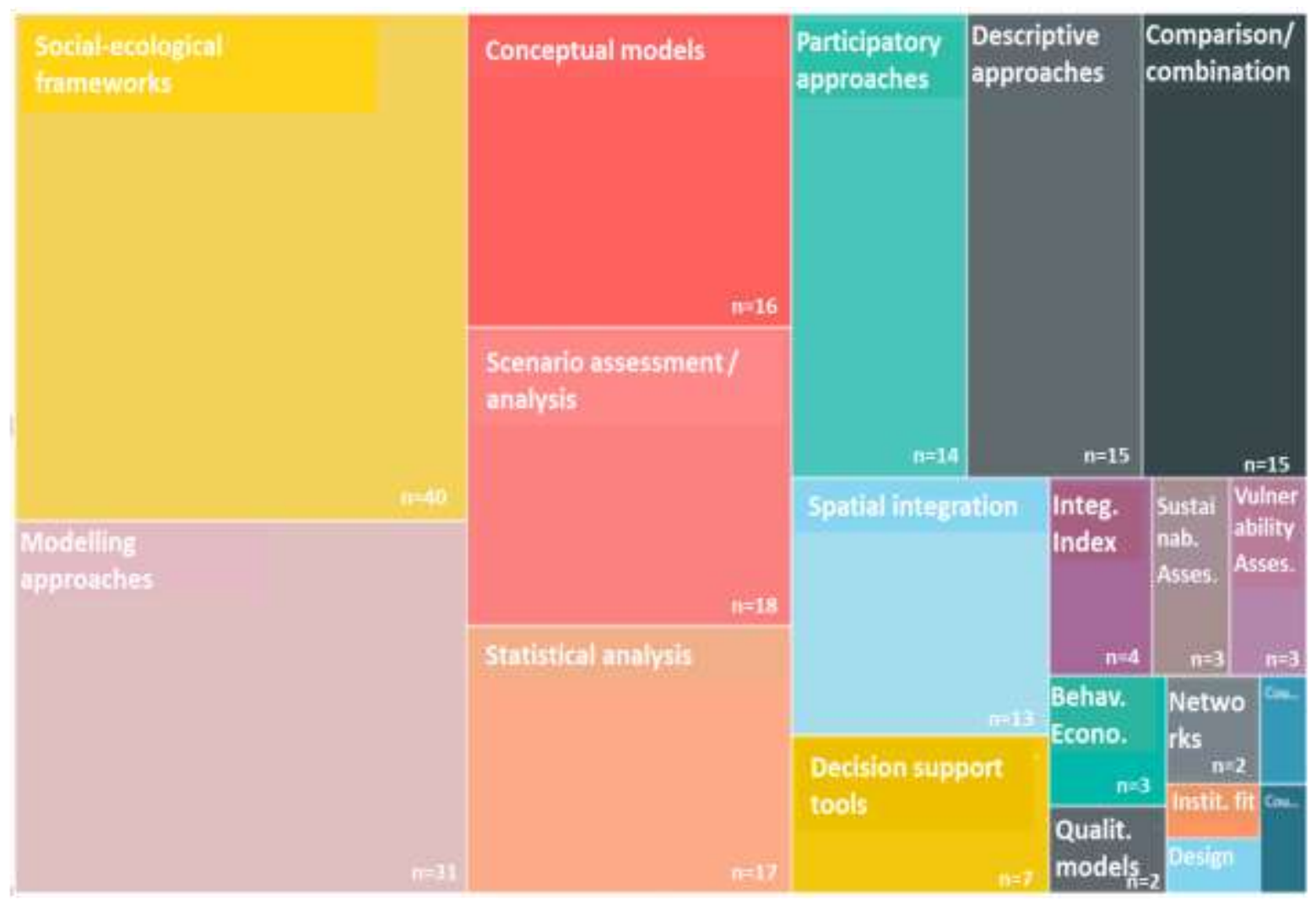

Fig. A4.3 Methods used in social-ecological research $(n=110)$. Area of each quadrant denotes proportion. Each paper was assigned to one method or more. Institutional fit and telecoupling were found only once our sample. Social-ecological frameworks used include the Social-ecological Systems framework $(n=9)$, the Resilience framework $(n=11)$, the Ecosystem Services framework $(n=9)$, the Driver-Pressure-State-Impact-Response framework $(n=5)$, the Management Strategy Evaluation framework $(n=2)$, the Sustainable Livelihoods framework $(n=1$; ref), and the PressureState-Response framework $(n=1)$. Modelling approaches used include agent-based modelling $(n=8)$, simulation modelling $(n=8)$, dynamic modelling $(n=7)$, system modelling $(n=6)$, bio-economic modelling $(n=5 ;$ ref $)$, integrated modelling $(n=4)$, bayesian belief networks $(n=2)$, and game theoretic modelling $(n=1)$. 
Table A4.2. Average number of tools used by studies with different levels of integration. Likert scale from 1(minimal integration) to 5 (a great amount of integration).

\begin{tabular}{|lr|}
\hline Integration rating & $\begin{array}{r}\text { Average number of tools } \\
\text { used }\end{array}$ \\
\hline $1(\mathrm{n}=22)$ & 2 \\
$2(\mathrm{n}=10)$ & 2.3 \\
$3(\mathrm{n}=47)$ & 2.7 \\
$4(\mathrm{n}=12)$ & 2.4 \\
$5(\mathrm{n}=10)$ & 3.5 \\
Total $(\mathrm{n}=100)$ & 2.5 \\
\hline
\end{tabular}

Table A4.3. Integration rating by tool used

\begin{tabular}{|c|c|}
\hline Tools used in social-ecological studies & $\begin{array}{l}\text { Average } \\
\text { integration } \\
\text { rating }\end{array}$ \\
\hline Scenario assessment/analysis $(\mathrm{n}=18)$ & 3.0 \\
\hline Statistical analysis of social and ecological data $(n=17)$ & 2.4 \\
\hline Spatial integration of social and ecological data $(n=13)$ & 3.5 \\
\hline Participatory approaches $(\mathrm{n}=14)$ & 2.9 \\
\hline Integrated index $(n=4)$ & 3.0 \\
\hline Social-ecological systems framework $(n=9)$ & 3.1 \\
\hline Resilience framework/Adaptive capacity/Panarchy/Adaptive cycle $(n=11)$ & 2.1 \\
\hline Ecosystem services framework $(n=9)$ & 3.1 \\
\hline Driver-Pressure-State-Impact-Response (DPSIR) $(n=5)$ & 3.8 \\
\hline Descriptive approaches (case study analysis, historical analysis) $n=18$ & 2.8 \\
\hline Decision support tool/approach $(\mathrm{n}=7)$ & 2.7 \\
\hline $\begin{array}{l}\text { Conceptual models (e.g. mental models, casual-loop diagrams, cognitive maps, fuzzy } \\
\text { maps/models) } n=16\end{array}$ & 2.7 \\
\hline Collection/comparison/combination of social and ecological data $(n=15)$ & 2.4 \\
\hline System modelling $(n=6)$ & 3.3 \\
\hline Simulation modelling $(\mathrm{n}=8)$ & 3.0 \\
\hline Integrated modelling $(\mathrm{n}=4)$ & 4.8 \\
\hline Dynamic modelling $(\mathrm{n}=7)$ & 2.7 \\
\hline
\end{tabular}


Bio-economic modelling $(\mathrm{n}=5)$

3.2

Agent-based modelling ( $\mathrm{n}=9$ )

3.0

All tools

2.8 
Table A4.4 Average integration rating for studies that used/not used theory to drive the socialecological approach employed. Integration ratings were calculated for resilience theory $(2.4, n=17)$, Common-pool resource theory $(2.8, \mathrm{n}=10)$, and systems theory $(3.5, \mathrm{n}=10)$. All other theories had small sample size.

\begin{tabular}{|ll|}
\hline & \multicolumn{2}{l|}{ Integration } \\
Theory driving the approach? & rating \\
\hline No $(\mathrm{n}=53)$ & 3.0 \\
Yes $(\mathrm{n}=48)$ & 2.5 \\
Total & 2.8 \\
\hline
\end{tabular}

Table A4.5 Representation disciplines in empirical papers and betweenness centrality scores.

Analysis was done using the studies identified during the abstract review $(n=700)$ and was based on the classification system used by the Web of Science database, which assigns classification based on journal.

\begin{tabular}{|llll|}
\hline Discipline & $\begin{array}{l}\text { No. of } \\
\text { papers }\end{array}$ & $\begin{array}{l}\text { \% } \\
(\mathbf{n}=700)\end{array}$ & $\begin{array}{l}\text { Betweenness } \\
\text { centrality } \\
(\text { mean }=21.4 \\
\text { S.D. }=65.2)\end{array}$ \\
\hline Ecology & 379 & $54.1 \%$ & 137 \\
Environmental Sciences & 345 & $49.3 \%$ & 342 \\
Environmental Studies & 339 & $48.4 \%$ & 177 \\
Biodiversity Conservation & 75 & $10.7 \%$ & 34 \\
Geography & 56 & $8.0 \%$ & 7 \\
Engineering & 43 & $6.1 \%$ & 4.3 \\
Physical Geography & 40 & $5.7 \%$ & 3 \\
Economics & 38 & $5.4 \%$ & 11 \\
Urban Studies & 28 & $4.0 \%$ & 33 \\
Computer Science & 23 & $3.3 \%$ & 0 \\
Geosciences & 22 & $3.1 \%$ & 13 \\
Sociology & 20 & $2.9 \%$ & 1 \\
International Relations & 13 & $1.9 \%$ & 0 \\
Agriculture & 11 & $1.6 \%$ & 5 \\
Planning \& Development & 10 & $1.4 \%$ & 2 \\
Anthropology & & $1.3 \%$ & 0 \\
Zoology & & $1.1 \%$ & 0 \\
& & & \\
\hline
\end{tabular}




\begin{tabular}{|c|c|c|c|}
\hline Meteorology \& Atmospheric Sciences & 7 & $1.0 \%$ & 0 \\
\hline Water Resources & 6 & $0.9 \%$ & 1 \\
\hline Marine \& Freshwater Biology & 3 & $0.4 \%$ & 0 \\
\hline Mathematics & 3 & $0.4 \%$ & 0 \\
\hline Remote Sensing & 3 & $0.4 \%$ & 0 \\
\hline Biology & 2 & $0.3 \%$ & 0 \\
\hline Evolutionary Biology & 2 & $0.3 \%$ & 0 \\
\hline Forestry & 2 & $0.3 \%$ & 1.9 \\
\hline Genetics \& Heredity & 2 & $0.3 \%$ & 0 \\
\hline $\begin{array}{l}\text { Imaging Science \& Photographic } \\
\text { Technology }\end{array}$ & 2 & $0.3 \%$ & 0 \\
\hline Limnology & 2 & $0.3 \%$ & 1 \\
\hline Soil Science & 2 & $0.3 \%$ & 0 \\
\hline Energy \& Fuels & 1 & $0.1 \%$ & 0 \\
\hline Ethics & 1 & $0.1 \%$ & 0 \\
\hline Fisheries & 1 & $0.1 \%$ & 0 \\
\hline History \& Philosophy Of Science & 1 & $0.1 \%$ & 0 \\
\hline Plant Sciences & 1 & $0.1 \%$ & 0 \\
\hline Public Administration & 1 & $0.1 \%$ & 0 \\
\hline Statistics \& Probability & 1 & $0.1 \%$ & 0 \\
\hline
\end{tabular}

Table A4.6. Integration scores for studies that did/did not involve stakeholders at some point in the study (e.g. in the study design, for collecting data, for the delivery of outputs)

\begin{tabular}{|lr|}
\hline & $\begin{array}{r}\text { Integration rating } \\
(\mathrm{n}=47)\end{array}$ \\
\hline No one involved & 2.9 \\
Stakeholders were involved & 2.6 \\
Grand Total & 2.8 \\
\hline
\end{tabular}

